\title{
EVALUATION OF SURFACTANTS AS STEAM DIVERTERS/MOBILITY CONTROL AGENTS IN LIGHT OIL STEAMFLOODS: EFFECT OF OIL COMPOSITION, RATES AND EXPERIMENTAL CONDITIONS
}

\author{
By \\ S.M. Mahmood \\ D.K. Olsen \\ E.B. Ramzel
}

December 1991

Work Performed Under Cooperative Agreement No. FC22-83FE60149

\author{
Prepared for \\ U.S. Department of Energy \\ Assistant Secretary for Fossil Energy
}

Thomas B. Reid, Project Manager

Bartlesville Project Office

P. O. Box 1398

Bartlesville, OK 74005

Prepared by

IIT Research Institute

National Institute for Petroleum and Energy Research

P. O. Box 2128

Bartlesville, OK 74005 


\section{TABLE OF CONTENTS}

Page

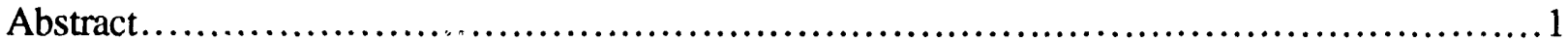

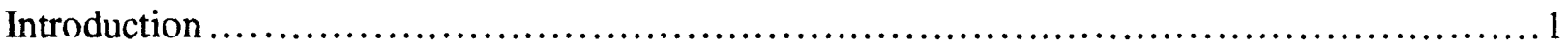

Previous Studies.................................................................

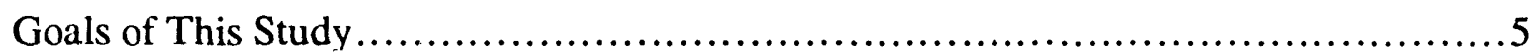

Relevance of Linear Steamfloods to Field Conditions .................................6

Experimental Equipment.............................................................. 7

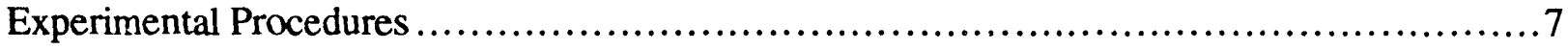

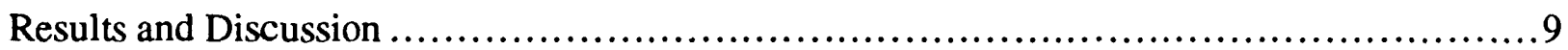

Foaming Behavior In Oil-Free Conditions ......................................

Effect of Oil on Foaming ...................................................... 10

Onset of Foaming and Emulsification......................................... 12

Effect of Oil Type on Foaming...................................................... 13

Effect of Salts on Foaming ................................................... 13

Effect of Injection Strategy .................................................... 15

Effect of Vapor-to-Liquid Fraction (VLF)..................................... 19

Effect of Injection Rate....................................................... 19

Effect of Noncondensible Gas Fraction............................................. 21

Role of BPR Performance..................................................... 24

Other Related Observations....................................................... 24

Observations and Conclusions................................................... 28

Acknowledgments........................................................... 29

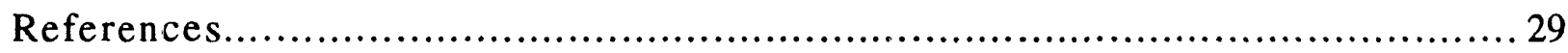

TABLES

1. Analysis of published field applications using steam foam diverters-uses and costs.....4

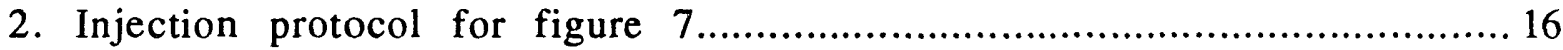

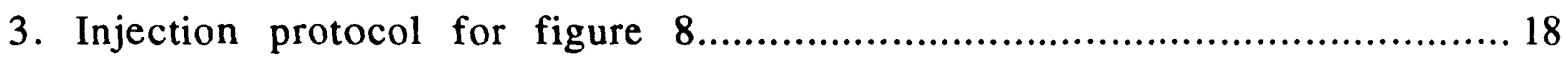

\section{ILLUSTRATIONS}

1. A schematic of the experimental equipment showing the location of temperature and pressure probes. 8

2. Pressure response during repeated cycles of concurrent steam, $\mathrm{N}_{2}$, and surfactant solution (1\% SD-1020) injection into a preheated sandpack initially saturated with water in the absence of oil 


\section{ILLUSTRATIONS-Continued}

3. Pressure responses during concurrent steam, $\mathrm{N}_{2}$, and surfactant solution

(1\% SD-1020) injection into a preheated sandpack in the presence and absence

of oil

4. Changes in physical appearance of effluents with decreasing oil saturations and the corresponding pressures during concurrent injection of ste:am, $\mathrm{N}_{2}$ and surfactant solution (1\% SD-1020) into a preheated sandpack initially saturated with oil and residual water.

5. Pressure response during concurrent injection of steam, $N$, and surfactant solution $(1 \%$ SD-1020) into a preheated sandpack in the presence of different oils ............ 14

6. Pressure response during repeated cycles of concurrent injection of steam, $\mathrm{N}_{2}$, and surfactant solution (1\% SD-1020) mixed with a salt $\left(1 \% \mathrm{NaHCO}_{3}\right)$ into a preheated sandpack initially saturated with water in the absence of oil

7. Pressure response history from a variety of injection strategies ending with a continuous injection strategy. Steam, $\mathrm{N}_{2}$ and surfactant solution (1\% SD-1020) were injected into a preheated sandpack initially saturated with water. The injection protocol is given in Table 2

8. Pressure response history from a variety of injection strategies beginning with a continuous injection strategy. Steam, $\mathrm{N}_{2}$ and surfactant solution (1\% SD-1020) were injected into a preheated sandpack initially saturated with water. The injection protocol is given in Table 3

9. Maximal pressure drop attainment in relation to the vapor contents of the injected fluids. Steam, $\mathrm{N}_{2}$ and surfactant solution (1\% SD-1020) were injected at arbitrary

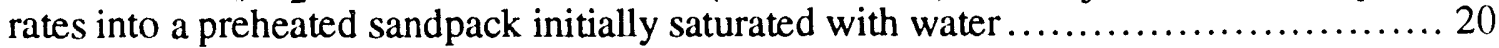

10. Pressure response history during a test in which the injection rates of steam, $\mathrm{N}_{2}$ and surfactant solution ( $1 \%$ SD-1020) were reduced stepwise in a proportion that maintained the same rate ratios. The sandpack was preheated and initially saturated

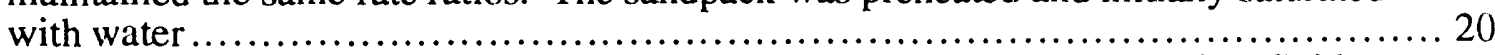

11. Delay in onset of foaming in an oil-free, preheated sandpack plotted against fluid injection rates. Steam, $\mathrm{N}_{2}$ and surfactant solution (1\% SD-1020) rates were also changed to maintain the same optimum rate ratios.

12. Maximal pressure drop attainment in an oil-free, preheated sandpack with variable fluid injection rates. Steam, $\mathrm{N}_{2}$ and surfactant solution (1\% SD-1020) rates were also changed to maintain the optimum rate ratios.

13. Pressure response history with stepwise reduction of noncondensible gas $\left(\mathrm{N}_{2}\right)$ rate. Steam and surfactant solution (1\% SD-1020) rates were unchanged. The sandpack was preheated and initially saturated with water.

14. Maximal injection pressure attainment in relation to the non-condensible gas $\left(\mathrm{N}_{2}\right)$ fraction. Steam, $\mathrm{N}_{2}$, and surfactant solution (1\% SD-1020) were injected into a preheated sandpack initially saturated with water.

15. Pressure response with two different backpressure regulators during concurrent steam, $\mathrm{N}_{2}$, and surfactant solution (1\% SD-1020) injection into a preheated sandpack . 25 


\section{ILLUSTRATIONS-Continued}

16. Pressure response with two different backpressure regulators during concurrent steam, $\mathrm{N}_{2}$, and surfactant solution (1\% SD-1020) injection into a preheated sandpack

17. An outline of pressure distributions: (a) Expected profiles during a constant rate advancement of a lower mobility fluid, (b) Observed profiles during steam-

foam displacement experiments...

18. Time versus pressure plot showing foam stability in a static condition.... 28 


\title{
EVALUATION OF SURFACTANTS AS STEAM DIVERTERS/MOBILITY CONTROL AGENTS IN LIGHT OIL STEAMFLOODS: EFFECT OF OIL COMPOSITION, RATES AND EXPERIMENTAL CONDITIONS
}

\author{
S. M. Mahmood, D. K. Olsen and E. B. Ramzel
}

\begin{abstract}
A series of experiments was performed to evaluate the effectiveness of commercially available surfactants for steam-foam EOR applications in light oil reservoirs. The experiments were performed in a 3-ft-long, 1-1/2 in.-diameter cylindrical sandpack of about 1 darcy permeability. The sandpack and injected fluids were preheated to $430^{\circ} \mathrm{F}$ at $155 \mathrm{psi}$. The main objective of these tests was to investigate the effectiveness of several surfactants in providing mobility control under a variety of conditions expected in light-oil steamfloods. Thus, maximum pressure-rise and foam-bank buildup/decay were noted as operating conditions were changed in a test or in various tests. Tests were performed with various oil types, sacrificial salts, injection rates, injection strategies, vapor-to-liquid fractions (VLF), and steam/ $\mathrm{N}_{2}$ ratios (SNR).

Key observations are summarized here. Two surfactants were highly effective in oil-free and low-oil conditions in reducing mobility insofar as the injection pressure did not surpass the steam saturation pressure. Total fluid injection rate - when each fluid rate was changed in the same proportion - correlated with the onset of foaming. Foamability increased exponentially with increasing VLF. Peak pressure drop correlated with SNR (at test conditions). Foam was maintained over significant durations only when surfactant was injected frequently or continuously. Addition of weak alkaline agents to surfactant had only a modest effect on foaming. Foaming was somewhat influenced by the pulsations in backpressure induced by a mechanical backpressure regulator (BPR). Higher pressures were observed with a more precisely controlled electronic BPR. Proper formulation and design are deemed to be critical for successful steam-foam treatments.
\end{abstract}

\section{INTRODUCTION}

Steamflooding, the most common enhanced oil recovery process in current use, has been mostly used for the production of heavy oils (API $<20^{\circ}$ and $>1,000 \mathrm{cP}$ ) from shallow formations, which typically offer high thermal viscosity reduction with relatively low heat losses to the surroundings. Light-oil reservoirs are traditionally considered good waterflooding candidates, but several pilot projects, ${ }^{1-4}$ laboratory studies, ${ }^{5-14}$ and computer simulation results ${ }^{15-23}$ have indicated that steamflooding could also be a viable process because of significant distillation of 
light oils by steam. This technology is being successfully applied to light oils in the world's largest EOR producing project, the Duri steamflood in Indonesia. ${ }^{24}$ A steam-foam field trial in Midway-Sunset (CA)field was reported to be successful in increasing sweep efficiency and producing incremental oil. ${ }^{25}$

A comparison of steamflood performance in displacing light and heavy crude oils was reported recently by Sarathi, Roark, and Strycker ${ }^{26}$ using four light crude oils ( $30^{\circ}$ to $48^{\circ} \mathrm{API}$ ) and a heavy oil $\left(14^{\circ} \mathrm{API}\right)$ in a physical 2-D model. In addition to recovery histories, the composition of produced and residual oils was determined at various intervals and at the end of the run. Their laboratory results showed that production of light oils, although strongly influenced by their chemical composition, was typified by an early production response to steam injection, yielding 55 to $65 \%$ of original oil-in-place (OOIP) at a steam-oil ratio (SOR) of 10 . Significant steam override was observed and identified as a potential problem for light oil displacements, contrary to the earlier simulation studies which indicated only minimal gravity segregation of steam in light oil reservoirs. Their conclusions were based on temperature profiles showing gravity tongues, higher residual-oil saturations at the bottom of the model, and iower oil recoveries in comparison to similar tests conducted in linear sandpacks. They observed that Hong's 22 conclusion of a piston-like steamfront advancement in light oil reservoirs was not validated based on data from their 2-D laboratory experiments. In view of their study suggesting that frontal instability may be significant in some steam injection operations in light-oil reservoirs, a study of the use of mobility control techniques becomes important.

Foam - a dispersion of surfactant, gas, and liquid - has been shown to be attractive for fluid (steam) diversion or mobility control. Foam offers a resistance to flow that is orders of magnitude higher than that of any of its components. Laboratory tests and field trials have shown that surfactants reduce the mobility of injected steam, 27-39 which is attributed to foam generation. Foam, due to its low mobility and blocking characteristics, has been shown to increase oil recovery by diverting injected steam to unswept regions. A unique feature of foam is "selective plugging," i.e. its preference in blocking the flow in relatively larger channels and oil-depleted regions, thereby minimizing the undesirable side effect of loss in overall injectivity.

Comprehensive literature reviews have been published ${ }^{28-30}$ in which pertinent issues of steam diversion by foam have been discussed. Eson and Cooke 27 describe the chronological development of steam-foam field testing summarized in this and the following two paragraphs. It started as cyclic steam-foam stimulation and was later expanded to steamdrives. Three variations of steamdrive were widely tested-slug type, continuous, and semi-continuous.

Slug type applications continued to dominate before the end of 1979. Continuous injection was then field tested and showed to be technically effective. However, the high consumption of surfactant and $\mathrm{N}_{2}$ in this technique made it economically less lucrative, especially during low oil 
prices. The semicontinuous application of the steam foam process was initiated by Chevron ${ }^{40}$ in 1983, and continues to receive much attention because of its more favorable economics.

Most of the field tests have produced substantial incremental recoveries. Exceptions are a test in Cat Canyon (CA) field, which was ineffective because the surfactant solution was unstable at the operating temperature of $550^{\circ} \mathrm{F}\left(288^{\circ} \mathrm{C}\right)$, and a test in San Ardo (CA) field, which was successful in altering the steam entry, but was insufficient in length and volume for the results to be extrapolated to the field scale. Both of these were slug-type tests.

In most cases, the application of foam has been cumbined with mature steamdrives (10 or more years of steam injection). An exception is the Bishop lease steam-foam pilot in Kern River (CA) field, ${ }^{41}$ which was under active steamflood for only a year before foam injection started. Incremental oil was recovered with an improvement in oil-steam ratio in almost all field pilots.

Most reports in the literature describing steam-foam projects do not give a breakdown of the amount of increase in oil production that is directly attributable to foam; neither do they indicate whether the steam-foam process resulted in incremental ultimate oil recovery. However, most case studies on steam-foam pilots showed an improvement of the cumulative oil-steam ratio, which is equated with an increase in net oil recovery. This increase is attributed to conservation of steam with accelerated production and results in the saving of crude oil that would otherwise be burned as fuel for generating steam. The improvement in oil-steam ratio is likely to be higher for a steamfoam project applied to a nonmatured steamarive reservoir. More favorable results are expected when the steam-foam process is applied soon after steam breakthrough rather than waiting until the conventional steamdrive has reached the economic limit. 42

Although the effectiveness of the steam-foam process has shown great potential, the economic benefits are still in question. Some promising field-scale economic analyses have been published, 43 yet other operators report that previous foam applications have at best provided a break-even return on the additional investment. ${ }^{27}$ High surfactant losses in the reservoir, the injection of a non-condensible gas $\left(\mathrm{N}_{2}\right)$, and the cost of steam generation are the primary costintensive items for a steam foam project. Table 143 gives a survey of the incremental cost of added surfactant incurred by several operators.

Injection of surfactants into porous media to optimize oil recovery is still an art rather than a science. Foam mobility in the vicinity of the injection well is much more important than that further into the reservoir, because in radial flow reservoirs the flow resistance is concentrated near the wellbore, especially if crossflow is minimal. 42 Previous studies $37-39,41$ have shown the process to be sensitive to (1) the type and saturation of oil, (2) the type and concentration of the surfactant solution, (3) slug injection strategy, (4) the vapor-to-liquid fraction, and (5) injection rates. 
TABLE 1. - Analysis of published field applications using steam foam diverters-uses and costs

\begin{tabular}{|c|c|c|c|c|c|c|}
\hline \multirow[b]{2}{*}{ Ref. $^{1}$} & \multirow[b]{2}{*}{ Operator } & \multirow[b]{2}{*}{ Field } & \multirow[b]{2}{*}{ Sand } & \multirow[b]{2}{*}{ Treatment } & \multicolumn{2}{|c|}{$\begin{array}{c}\text { Surfactant consumption } \\
\text { and cost } \\
\text { Der incremental bbl }\end{array}$} \\
\hline & & & & & $\mathrm{lb} / \mathrm{bbl}$ & $\$ / b b l$ \\
\hline Greaser $^{44}$ & Getty & $\begin{array}{l}\text { Kern } \\
\text { River }\end{array}$ & & Slug & 0.6 & 0.49 \\
\hline Farrell ${ }^{45}$ & $\begin{array}{l}\text { Petro } \\
\text { Lewis }\end{array}$ & $\begin{array}{l}\text { Kern } \\
\text { Front }\end{array}$ & - & Slug & 2.0 & 1.80 \\
\hline \multirow[t]{3}{*}{ Doscher $^{46}$} & $\begin{array}{l}\text { Santa Fe } \\
\text { Energy }\end{array}$ & $\begin{array}{l}\text { Midway } \\
\text { Sunset }\end{array}$ & - & Cont. & 0.7 & 0.57 \\
\hline & Conoco & $\begin{array}{l}\text { Cat } \\
\text { Canyon }\end{array}$ & - & Cont. & \multicolumn{2}{|c|}{$\begin{array}{l}\text { Ineffective surfactant due to } \\
\text { high temperature }\end{array}$} \\
\hline & Texaco & San Ardo & - & Cont. & \multicolumn{2}{|c|}{$\begin{array}{c}\text { Too small a slug and too short } \\
\text { a pilot period }\end{array}$} \\
\hline \multirow[t]{2}{*}{ Palzek $^{41}$} & Shell & $\begin{array}{l}\text { Kern } \\
\text { River }\end{array}$ & Mecca & Cont. & 7.1 & 5.44 \\
\hline & & & Bishop & Cont. & 15.1 & 11.58 \\
\hline Mohammadi $^{47}$ & Unocal & $\begin{array}{l}\text { Santa } \\
\text { Maria }\end{array}$ & - & Cont. & 8.7 & 11.75 \\
\hline Mohammadi $^{48}$ & Unocal & $\begin{array}{l}\text { Midway } \\
\text { Sunset }\end{array}$ & - & Cont. & 5.8 & 4.5 \\
\hline SUPRI $^{49-50}$ & $\begin{array}{l}\text { Petro } \\
\text { Lewis }\end{array}$ & $\begin{array}{l}\text { Kern } \\
\text { River }\end{array}$ & - & Semi-cont. & 3.3 & 4.42 \\
\hline Ploeg 40 & Chevron & $\begin{array}{l}\text { Midway } \\
\text { Sunset }\end{array}$ & - & Semi-cont. & 1.0 & 1.35 \\
\hline Ploeg 40 & Chevron & $\begin{array}{l}\text { Midway } \\
\text { Sunset }\end{array}$ & Monarch & Semi-cont. & 3.3 & 4.42 \\
\hline
\end{tabular}

${ }^{1}$ First author of paper.

Salt tolerance of the surfactant is an important consideration in reservoirs containing or receiving high salinity brines. Certain salts have been used successfully as sacrificial agents ${ }^{34-35}$ to reduce the surfactant losses caused by adsorption, partitioning, and precipitation (because of surfactant-clay cation-exchange). Other side-benefits cited ${ }^{33}$ for salt treatment include in situ $\mathrm{CO}_{2}$ generation (which serves as a noncondensible gas), faster reduction of residual oil saturation due to emulsification, and acidic crude oil neutralizaticil. Salt sensitivity, therefore, is an important consideration for the steam-foam process.

In contemporary research, process optimization for steam-foam field applications has been emphasized, in addition to fundamental studies of foam generation and flow in porous media. In this study, the sensitivity of high-temperature steam-foam surfactants to these parameters is determined and evaluated. 


\section{Previous Studies}

In previous studies ${ }^{12}$ conducted at NIPER, the effects of oil and rock properties on the performance of light-oil steamfloods were investigated. These studies were conducted primarily for evaluation of rock-fluid interactions under simulated field conditions. A summary of earlier findings is as follows. In the first study, conducted in 1984, the effects of rock/fluid properties on the performance of light-oil steamfloods were investigated. Experiments were performed in fired Bere $:$ sandstone cores of 1.5 -inch $(3.8 \mathrm{~cm})$ diameter and 26 -inch $(66 \mathrm{~cm})$ length, under simulated field conditions of pressure, temperature, and overburden pressure. Steamflood recoveries in both secondary and tertiary modes were determined, i.e. tests were performed both before and after waterflooding. Some of the results reported by Madden and Sarathi ${ }^{12}$ are presented below:

(a) Ultimate recoveries were as high as $86 \%$ of the original oil-in-place.

(b) Residual oil saturation was relatively independent of initial oil saturation, but premature steam breakthrough resulted in the case of high initial water saturation.

(c) The chemical composition of the crude affected ultimate oil recovery; crudes with large amounts of polar compounds yielded lower recoveries.

(d) The ultimate oil recc very was relatively independent of the quality and rate of steam injection. However, steam injected at higher qualities and higher rates recovered oil faster.

(e) The ultimate oil recovery was independent of the permeability of the cores, even though the lower permeability cores encountered greater heat losses because of slower steamfront advance.

A critical review of previous light-oil steamflood studies by Strycker and Sarathi 13 included most field projects, research projects, and simulation studies. A nortion of the work described in the following pages of this report was presented as a paper, entuled "Sensitivity of Steam-Foam Surfactants to Oil, Salt and Experimental Conditions," at the American Chemical Society 65th Colloid and Surface Science Symposium, June 17-19, 19:1.

\section{Goals of This Study}

Despite the promise shown by earlier studies, few full-scale light-oil steamfloods have been undertaken. One reason may be a scarcity of more quantitative information. To become a fully proven method, the economic and technical performance of light-oil steamflooding must be predictable. Simulation studies published so far have had many assumptions that limit their predictive ability.

Most of the previous experimental studies were focused on generating crude-oil/steamdistillation data and correlating steam-distillation yields with crude gravity. Some studies were focused on the overall recovery and the temperature distribution in linear models. More studies 
are needed to investigate the role of mobility control in light oil steamflooding. The effects of major important variables on the steam-foam process, a rather promising technique, need to be addressed. The primary goal of this project was to identify those parameters to which the steamfoam process is so highly sensitive as to dictate its success or failure.

\section{Relevance of Linear Steamfloods to Field Conditions}

The flow of steam in linear models is predominantly piston-like and does not permit gravity override of steam to occur. Gravity override of steam can occur in 3-D systems such as rectangular sandpacks or hydrocarbon reservoirs. Because of sweep inefficiencies caused by gravity override and other frontal instabilities, linear steamfloods are likely to yield higher oil recoveries than those of 2 - or 3-D systems.

To determine the extent of differences between linear and 2-D steamfloods, selected results from a previous study 12 were compared with the 2-D results. 51 Experiments were conducted in linear sandpacks with permeabilities similar to those of 2-D sandpacks. The comparisons were made for runs carried out under similar conditions of steam pressure, injection rate, and steam quality. Three runs ${ }^{14}$ made in 2-D sandpacks which were previously waterflooded were compared with those of a previous linear test to determine the effect of initial water saturation on oil recovery. The effect of high initial water saturation on oil recovery was only minor in linear steamfloods, but the opposite was true for 2-D steamfloods. The overall recovery decreased with an increase in water saturation. Steamdrive as a tertiary process recovered less oil in 2-D runs than in linear runs.

The above studies show that linear models may not be adequate to represent frontal instabilities likely to be encountered in reservoirs. The results from 2-D models are not directly applicable to most reservoirs because of scaling differences. For example, gravity segregation in 2-D models may not be akin to reservoir conditions for steamfloods because of differences in heattransfer characteristics. The cooler temperature ahead of the front in many reservoirs condenses steam, thus improving the frontal stability. The 2-D models, on the other hand, encounter rapid preheating along metallic structural plates. Two-dimensional models also differ from reservoirs in flow geometry, with planar flow in the former with constant total velocity and radial flow in the latter, with rapidly decreasing fluid velocities away from the wellbore.

Linear sandpack models, however, are appropriate for evaluating the foamability of a suiractant, at least for initial screening. ${ }^{28}$ Linear tests in the absence of oils and clays are also required to allow direct comparisons with other studies. 28 Linear model studies are also complimentary to 2-D studies, and provide useful data for simulation studies. This is precisely the context in which the results of this study should be interpreted. 


\section{EXPERIMENTAL EQUIPMENT}

The experimental setup used for these tests included a linear steamflood sandpack (34.5-in.long, 1.5-in.-diameter), steam-nitrogen-liquid delivery system, and pressure/temperature control and monitoring systems. The temperature, pressure, and volume throughputs (both injected and produced) were recorded at 30- to 60-minute intervals from a combination of digital and analog readouts. Pressure drops were recorded continuously on two strip chart recorders. The experimental system is shown in figure 1.

Clean quartz sand of 100-140 mesh size was used to prepare the sandpack. The sand was compacted using a small pneumatic vibrator. The resulting pore volume of the sandpack was 510 $\mathrm{mL}$, the porosity was $51 \%$, and the initial permeability to water was about 1.15 darcies. Both porosity and permeability values are gross approximations.

Heating tapes, overlain by insulating material, were wrapped around the metallic coreholder and the plumbing. Sandpack temperatures near the injection and production ports were monitored using thermocouples. The model temperature was maintained at about $430^{\circ} \mathrm{F}$ by manually adjusting voltage regulators. One thermocouple was installed very close to the froduction end to monitor the coolest point in the sandpack. The temperature at this location averaged $350^{\circ}$ to $375^{\circ} \mathrm{F}$ from the beginning of the test, and the pressure was near the backpressure regulator (BPR) setting of 155 psi with and without surfactant. This interrelationship is discussed in the Results and Discussion section.

Injected nitrogen and surfactants were preheated to $430^{\circ} \mathrm{F}$ by passing them through coiled metal tubing placed inside a temperature-controlled oven. The heated fluid temperatures (including $\mathrm{N}_{2}$ ) were recorded at two points before entry to the sandpack. The sandpack temperature was recorded $1 \mathrm{in}$. inside the sandpack at the production end, and at two points on the outer surface of the steel casing (close to both the injection and production ends).

Figure 1 shows the location of temperature and pressure probes. Differential pressures were read across the entire model and across the first foot of the injection side. Pressures were also noted on separate gauges at the injection and at the production control valve of the model. Before starting surfactant injection, the equilibrium pressure of the model was 155 psi.

\section{EXPERIMENTAL PROCEDURES}

The tests were performed at idealized isothermal conditions, with a nominal test temperature of $430^{\circ} \mathrm{F}$. The backpressure control was set at $155 \mathrm{psi}$. Under these conditions, the injected steam entered the sandpack superheated. Before the start of each oil-free series of experiments, the sandpack was cleaned - primarily to remove residual surfactant - by injecting 3 or more pore 


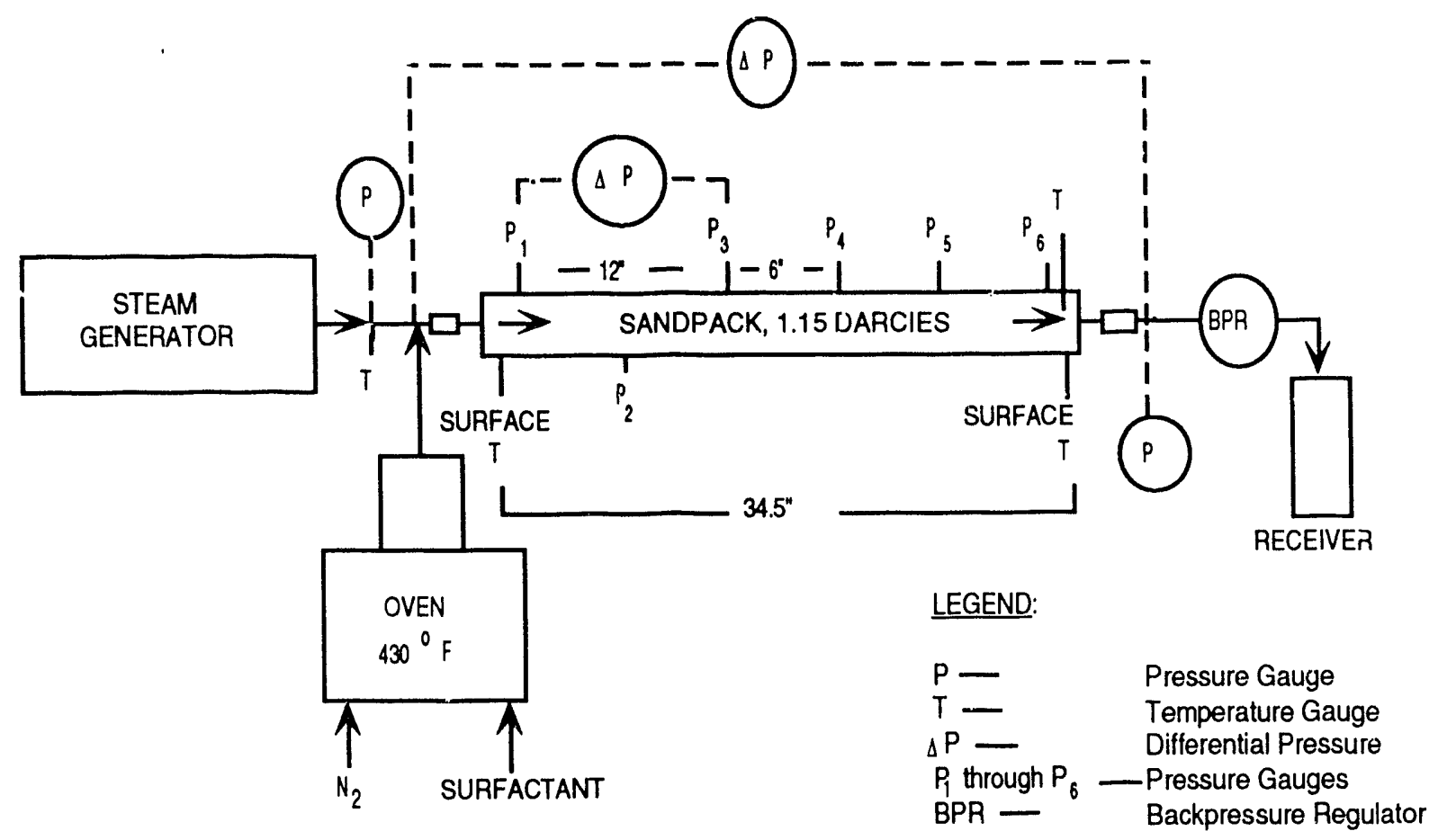

FIGURE 1. - A schematic of the experimental equipment showing the location of temperature and pressure probes.

volumes (PV) of 1:1 isopropyl alcohol/water, followed by water and $\mathrm{N}_{2}$, all preheated to the test conditions and at typical liquid and gas rates of 3.33 and $6.8 \mathrm{~mL} / \mathrm{min}$, respectively (rateequivalents at standard room conditions). After the tests involving crude oil, the sandpack was first cleansed of oil by injecting 4 or more pore volumes of $1: 1$ toluene/acetone at room temperature by the procedure described above.

Steam and $\mathrm{N}_{2}$ flow were stabiiized at specified test rates, typically for 2 to 6 hours of noninterrupted injection, prior to surfactant injection. The oil-free tests were then started by injecting preheated surfactant (mixed with salts in some tests). Injection rates during the tests were often changed depending on the test objectives.

Experiments involving oil required the following additional preparatory steps, in sequence, prior to surfactant injections: oil flooding, waterflooding, and then steamflooding to residual oil saturation (approximate average of $8 \%$ ). The oils were crudes from steamflood projects (Kern River, a California light oil reservoir being steamed, and Teapot Dome).

Three cycles were repeated for most oil-free tests to obtain higher confidence in the results. Each cycle had two steps: pressure build-up and pressure decline. The former involved surfactant injection, and the latter its termination while the injection of other fluids continued. The cutoff 
conditions were 30 to 60 minutes after the maximum pressure was attained, and several hours after the pressure fell to $155 \mathrm{psi}$ (the backpressure regulator setting), respectively. Only one cycle was carried out in most oil-containing tests for each set of operating conditions because of longer test durations.

\section{RESULTS AND DISCUSSION}

The results presented in the following sectiuns fall in two categories: oil-free and oilcontaining test: for surfactant-induced mobility reduction. A summary of the observations presented below is as follows. No foaming was observed as long as the remaining oil saturation was significantly higher than residual oil saturation. The onset of foaming was much quicker in oil-free tests than in the oil-containing tests which required additional fluid injection to lower oilsaturation (below an estimated value of $10 \%$ ). Once foaming was initiated, the pressure buildup in oil-containing tests was similar to that of oil-free tests. Low-salt tests (e.g., $1 \%$ by weight) behaved similarly to the oil-free tests for all practical purposes. In view of these observations, further tests for investigating slug optimization techniques were performed in salt- and oil-free environments; presumably the results are also applicable to low-oil and low-salt conditions.

Foamability was largely dependent on total (cumulative) fluid velocities, vapor-to-liquid ratios (including both steam and $\mathrm{N}_{2}$ as vapor) and noncondensible gas $\left(\mathrm{N}_{2}\right)$ fractions. Some correlations are presented to show the effart of these parameters on foaming behavior. Results in this study were not influenced by the inverse relationship that often exists between heat-loss and steam injection rate because both the sandpack and fluids were preheated. The role of BPR performance on foaming efficiency was also investigated by comparing the test results using a very precise electronic BPR with those using a mechanical BPR. The electronic backpressure regulator was able to attain somewhat higher pressures than the mechanical BPR.

\section{Foaming Behavior in Oil-Free Conditions}

A series of tests was performed to observe foaming behavior in oil-free conditions. The sandpack was fully saturated with distilled water and pre-heated to the test temperature $\left(450^{\circ} \mathrm{F}\right)$. Steam, $\mathrm{N}_{2}$, and surfactant solution were concursently injected into the sandpack. The pressure rose due to foaming and leveled off. Surfactant injection was then stopped while steam and $\mathrm{N}_{2}$ injection continued. The pressure began to decline and sventually dropped to the base value (BPR setting, $155 \mathrm{psi}$ ). This gradual pressure buildup to the peak due to surfactant injection, followed by a gradual decline to the base value after surfactant injection termination, constituted one cycle. Several cycles in this sequence were carried out for most tests in this series. 
Three cycles of a typical no-salt, oil-free test are shown in figure 2 . The first cycle shows a delay in pressure response of $0.35 \mathrm{PV}$ of steam injection cold water equivalent (CWE), which was rather high for adsorption losses under this idealized clean-quartz environment, and might have been due to surfactant dilution at the early stages. Thie latter cycles, which were quite similar, showed a much smaller delay (0.06 PV), which can perhans be attributed to the lag time between the beginning of the surfactant solution injection into the tubing and its actual arrival at the sandpack.

On the basis of our experience in performing numerous steam-foam runs, the following conclusions are drawn. Chevron's 1\% Chaser SD-1020, the most commonly used surfactant in these tests, is effective in increasing the flow resistance to a level that causes the injection pressure to approach the saturation pressure of steam $\left(423 \mathrm{psi}\right.$ at $\left.450^{\circ} \mathrm{F}\right)$. However, continuous surfactant injection or frequent injection of small slugs is necessary to sustain such high pressures over extended durations. The foaming performance of $1 \%$ LTS-18, another widely tested surfactant solution, is about the same as that of $1 \%$ SD-1020 in reducing mobilities. Both the Chaser SD1020 and LTS-18 are proprietary surfactants.

Other investigators ${ }^{32,37}$ have observed an increase in flow resistance by a factor of 25 to 75 when steam injection was augmented with surfactant injection. Our results are comparable in mobility reductions and also suggest that the maximum reduction of mobility is contingent upon the steam saturation pressure as explained in a later section.

\section{Effect of Oil on Foaming}

In figure 3 , the results of steam $/ \mathrm{N}_{2}$ /surfactant floods in oil-free and oil-containing environments are compared. The pressure kick occurred after only $0.2 \mathrm{PV}$ of surfactant injection in an oil-free condition, whereas 1.2 PV injection was required when residual oil (after waterflood) was initially present.

After the pressure started building, it rose more rapidly in the oil-free test than in the oilcontaining test because in a high-oil-saturation environment, foaming was preceded by emulsification. The inflection in the oil-test curve is reflective of these changing roles of erzulsification and foaming. This point is further clarified in the following section.

Note that eventually, the peak pressures $(\approx 400 \mathrm{psi})$ in initially oil-containing tests approached those of the oil-free tests. It is inferred that the traces of oil remaining in the porous medium, after large fluid throughputs, did not inhibit foaming.

These results are in agreement with the published data, except that some experimental studies report only a modest efiact of reservoir oil on foam effectiveness. ${ }^{36}$ 


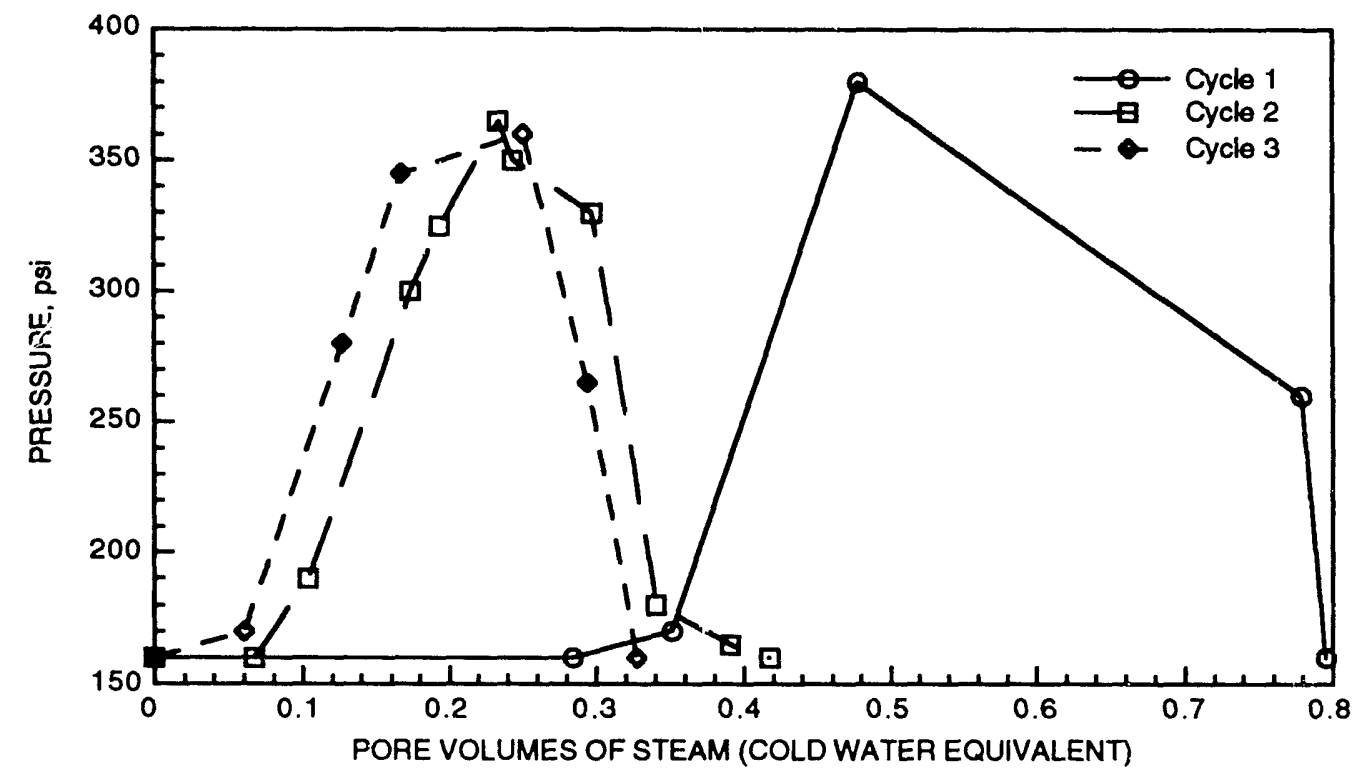

FIGURE 2. - Pressure response during repeated cycles of concurrent steam, $\mathrm{N}_{2}$, and surfactant solution (1\% SD1020) injection into a preheated sandpack initially saturated with water in the absence of oil .

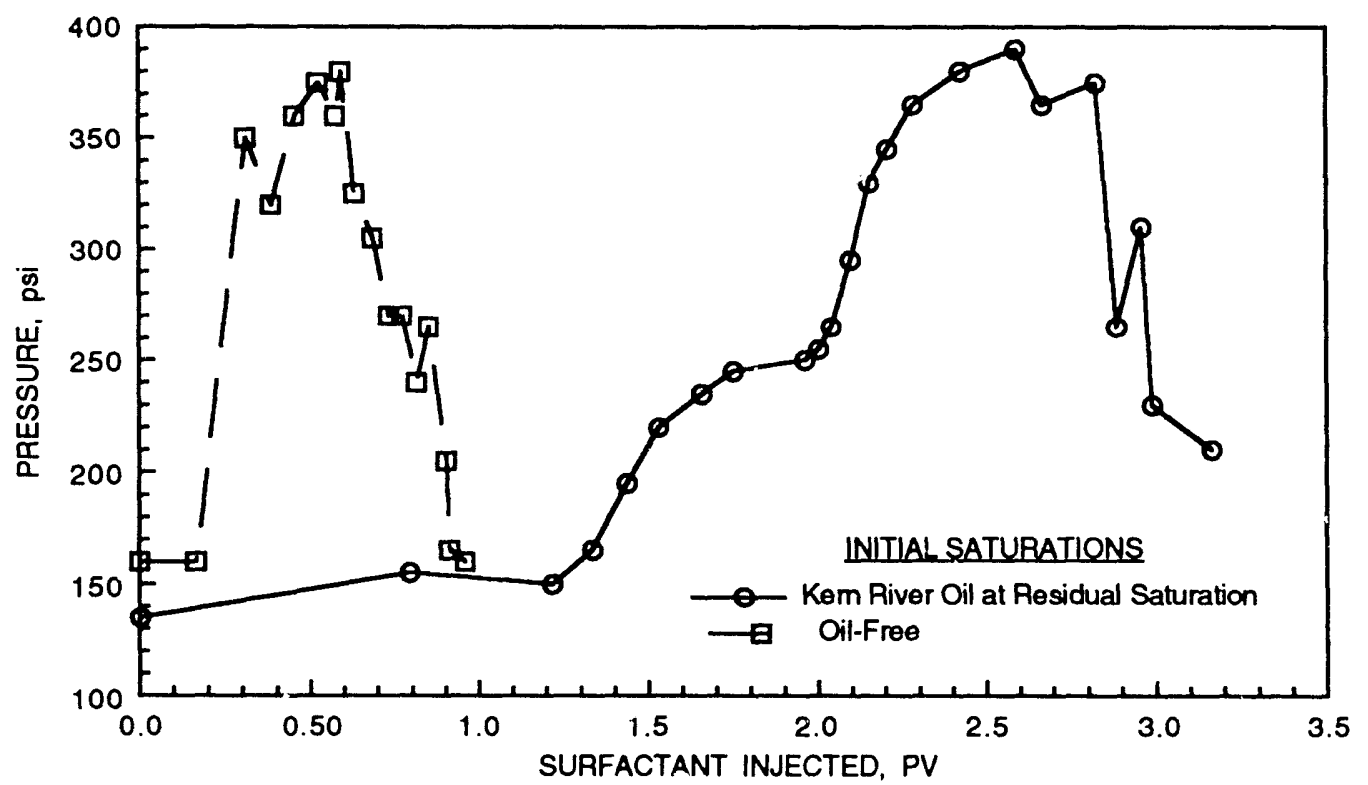

FIGURE 3. - Pressure responses during concurrent steam. $\mathrm{N}_{2}$, and surfactant solution (1\% SD-1020) injection into a preheated sandpack in the presence and ahsence of oil. 


\section{Onset of Foaming and Emulsification}

No means of positively identifying the existence of foam or an emulsion in the sandpack were available. The presence of foam-like dispersions in the effluents does not necessarily imply their existence in the sandpack; therefore, the effluent observations were used only in conjunction with the pressure response histories. In the following discussion, the terms "foaming" or "foam generation" apply to any situation in which the addition of surfactant to steam and $\mathrm{N}_{2}$ injection has resulted in a 100-fold or so increase in pressure drop. Any emulsion in the effluent, however, was presumed to have originated in the sandpack because of a more favorable environment in the porous medium.

Figure 4 describes the history of the physical appearance of effluents during two oilcontaining steam-foam tests. The early pressure response (at $10 \%$ oil saturation) was coincident with the beginning of oil/water emulsion production, and strong foam was produced near the maximum pressure drop (at $5 \%$ oil saturation). The onset of emulsification (as evidenced by microscopic observation of effluents) preceded the onset of foaming (as evidenced by a sudden rise in pressure) because the early environment of low surfactant concentration and high oil saturation was conducive to emulsification but inhibitive for foaming. During the transition interval between the first pressure kick and attainment of peak pressure, both foam and an emulsion were seen in the effluents.

The characteristics of various phases of emulsions were visually observed by microscopic examination in two tests. Light tan emulsions were composed of smaller oil-in-water emulsions (as determined by microscopic examinations) with a narrow size distribution: median size $\approx 4 \mu$, majority $\approx 2-8 \mu$, and rarely above $12 \mu$. Darker emulsions were also oil-in-water, but had a broader size distribution: median size $\approx 10 \mu$, majority $\approx 4-16 \mu$, and rarely above $20 \mu$.

The presence of oil in significant quantities impaired the formation of foam. There was little or no foaming as long as the oil remaining in the sandpack was in excess of steamflood residual saturation. Peak foaming, as inferred from the maximum pressure drop across the sandpack, occurred in most tests around 5\% oil saturation (determined by material balance). The amount of surfactant (1-2 PV) required in these experiments for lowering oil saturation to a point where peak foaming was attainable appears to be too high for economically viable field applications. In reality, however, the surfactant volume required in a linear sandpack - such as in this study - may not be indicative of the requirements in typical hydrocarbon reservoirs. The mobility control targets in many reservoir applications are those thin channels and tongues within the swept zone that act as a conduit for the bulk of the flow, but constitute only a small fraction of the formation. 


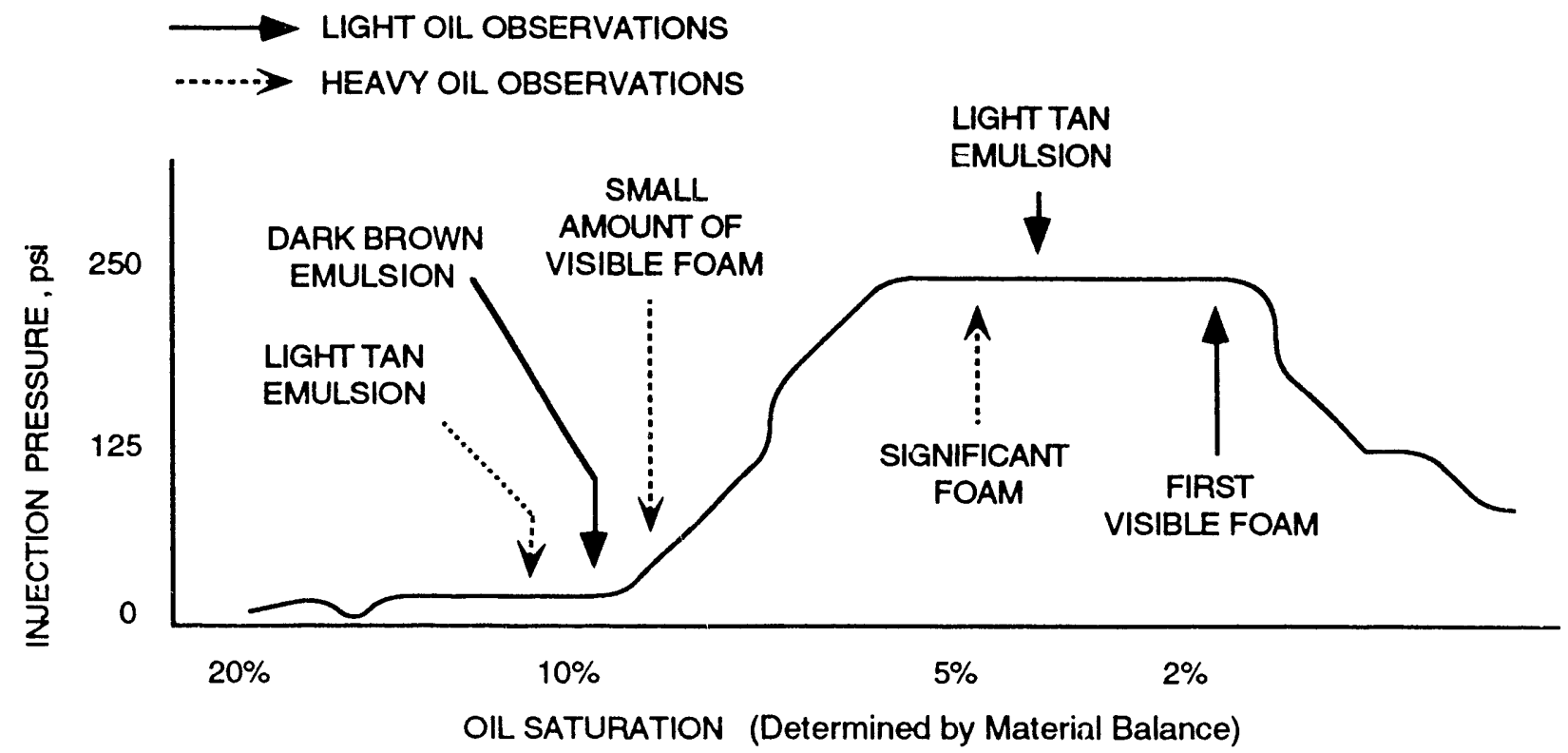

FIGURE 4. - Changes in physical appearance of effluents with decreasing oil saturation and the corresponding pressures during concurrent injection of steam. $\mathrm{N}_{2}$ and surfactant solution (1\% SD-1020) in $/ 0$ a preheated sandpack initially saturated with oil and residual water.

\section{Effect of Oil Type on Foaming}

In figure 5, the foaming performance of three oils (Kern River: $13^{\circ}$ API, Teapot Dome: $32^{\circ}$ API, and a California Light Oil: $27^{\circ}$ API) are compared. The peak foaming performance (maximum pressure drop) in each of the three tests containing different oils was about the same. As explained later in the Other Related Observation section, the injection pressure at the maximum pressure drop approached that of the steam saturation pressure. Similarly, the rate of pressure decline when surfactant injection was terminated was about the same in each test. However, the onset of foaming and the rate of pressure rise were different for each oil. A probable explanation is the variation in emulsification characteristics among the three oils. The higher the degree of emulsification, the earlier the pressure kick and the slower the rise in pressure drop. The microscopic displacement efficiencies for various oils may also vary because of the variable distillation rates, which might have contributed in influencing the foaming onset as well.

\section{Effect of Salts on Foaming}

Figure 6 shows a test comparable to the no-salt/oil-free test shown in figure 2, but with $1 \%$ sodium bicarbonate added to the surfactant. Comparison of figures 2 and 6 shows that the addition of salt resulted in an earlier pressure response but slower pressure buildup. The third cycle in 


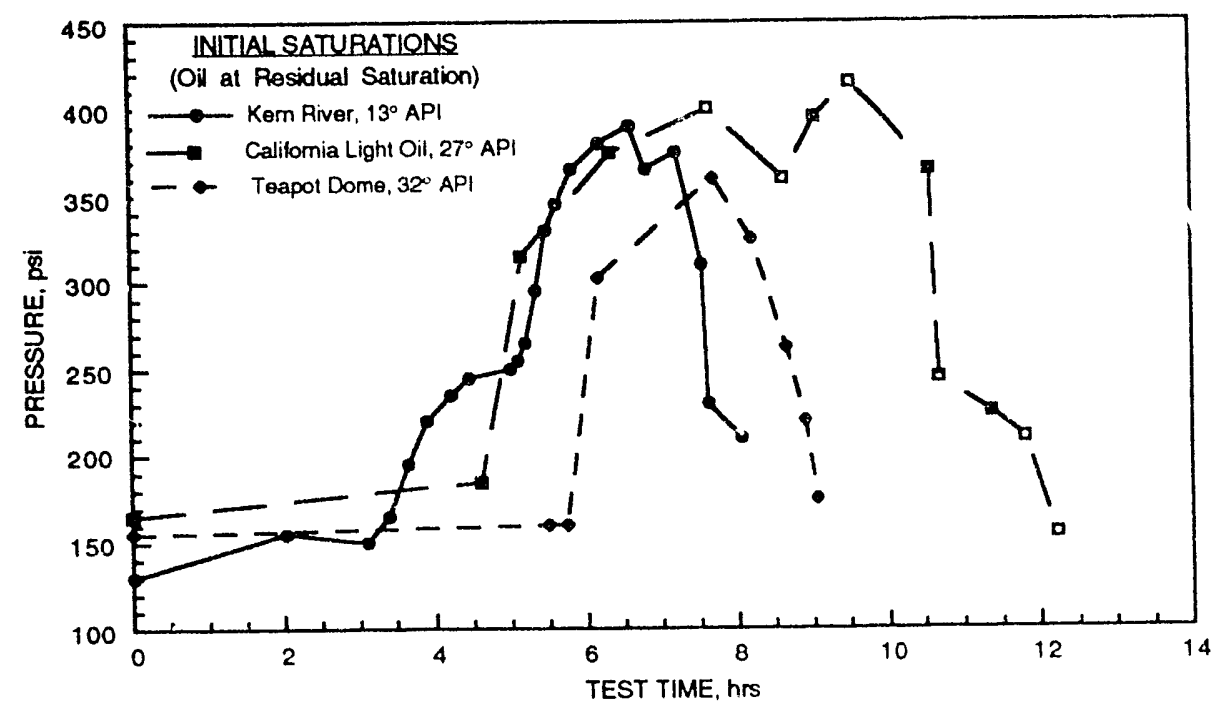

FGURE 5. - Pressure response during concurrent injection of steam, $\mathrm{N}_{2}$ and surfactant solution (1\% S1)-1020) into a preheated sandpack in the presence of different oils.

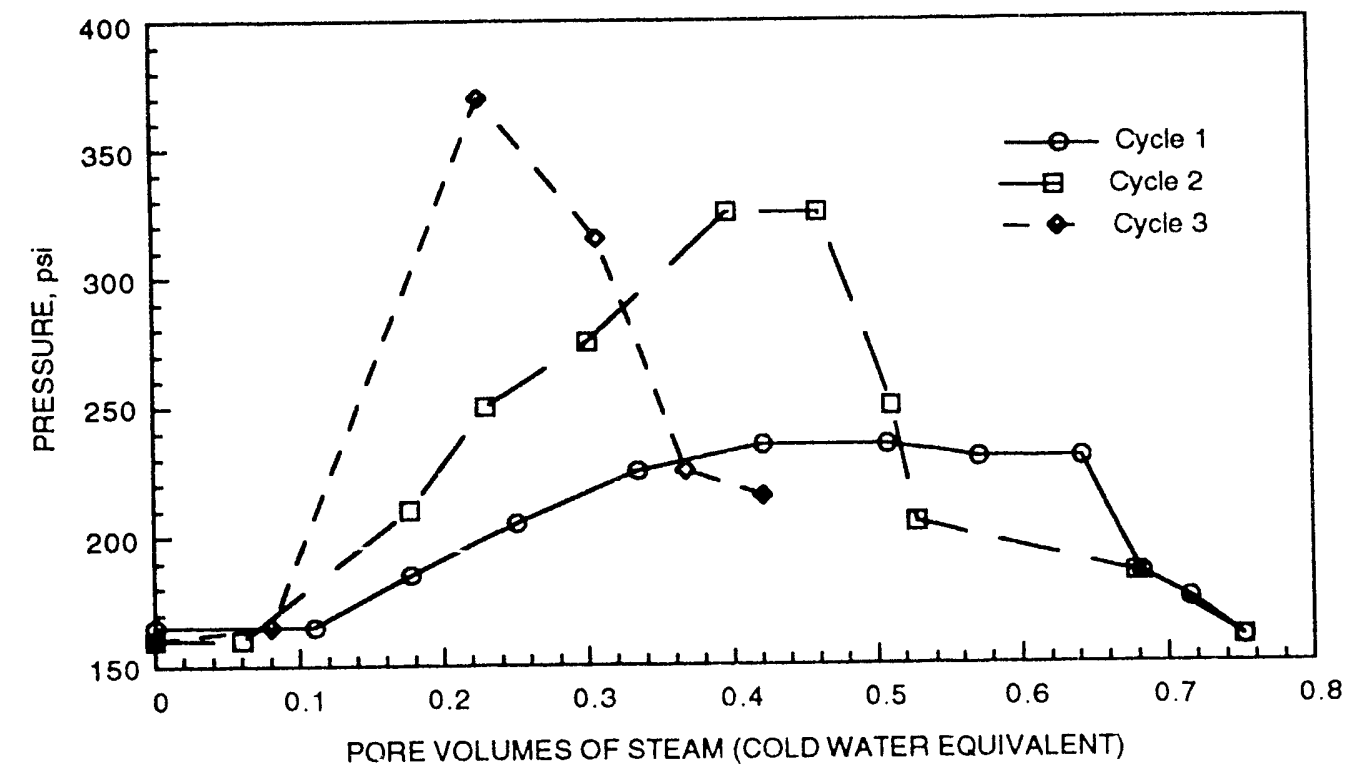

FIGURE 6. - Pressure response during repeated cycles of concurrent injection of steam, $\mathrm{N}_{2}$ and surfactant solution $\left(1 \%\right.$ SD-10\%20) mixed with a salt $\left(1 \% \mathrm{NaICO}_{3}\right)$ into a preheated sandpack initially saturated with water in the absence of oil. 
figure 6 shows behavior similar to the third cycle of no-salt tests shown in figure 2, i.e., an approximately similar delay in pressure kick (at $\approx 0.06 \mathrm{PV}$ ) and similar pressure buildup and decline rates. The second cycle was comparable to the second cycle of the no-salt test in pressureresponse time (both 0.06 PV); however, it showed a significantly lower rate of pressure buiidup than the salt-free test. The first cycle shows a pressure kick earlier than the first cycle of the no-salt test (0.11 vs. $0.35 \mathrm{PV})$, indicating that the salt acted as a sacrificial agent. However, the pressure buildup in this cycle was much slower than that in other cycles. It is possible that a rock/brine/surfactant interaction produced by-products that could have lowered the foamability of surfactant. It is also possible that surfactant adsorption characteristic might have been altered by the presence of salt. Future tests will include a determination of surfactant adsorption at the end of each cycle to understand this behavior.

Similar behavior was observed in tests initially containing waterflood residual oil (not shown in figures). In low-oil environments, addition of sodium salts to the surfactants ( $1 \% \mathrm{NaHCO}_{3}$, $1 \% \mathrm{Na}_{2} \mathrm{CO}_{3}$ or $(0.7 \% \mathrm{NaCl})$ only slightly impaired mobility reduction characteristics relative to the no-salt surfactant tests. In one test with $1 \%$ LTS-18 and $0.7 \%$ sodium chloride a slightly higher reduction in performance resulted, but foaming was still significant. The injection pressure in the first cycle of this test climbed to only $250 \mathrm{psi}$ as compared to the $280 \mathrm{psi}$ in a similar test with SD-1020. The test was discontinued (unintentionally) after the first cycle; hence, the performance for later cycles cannot be compared.

These results show that the above surfactants have moderate tolerance to salts. Thus, salts can be used in clayey sands as sacrificial agents without seriously deteriorating the foaming performance of these surfactants. They can also generate foam effectively in low salinity reservoirs.

The precipitation of surfactant and deterioration of foaming performance was more drastic at a higher salt concentration. A solution of $5 \%$ sodium bicarbonate and $1 \%$ Chaser SD-1()20 did not show any pressure buildup response. The solution disintegrated (at room conditions) into a fluffy white flocculate which was floating on a clear yellowish liquid. This precipitation was not apparently visible soon after it was prepared and during the test because of continuous heating of the surfactant feedstock.

\section{Effect of Injection Strategy}

Figure 7 shows results from variations in injection strategies encountered during a test in which surfactant, steam, and $\mathrm{N}_{2}$ rates were arbitrarily changed (without any systematic order). Table 2 outlines the injection protocol for this test. In the first part of the test, slugs of surfactant were injected, often with steam or both steam and nitrogen. Between each of these slugs, 


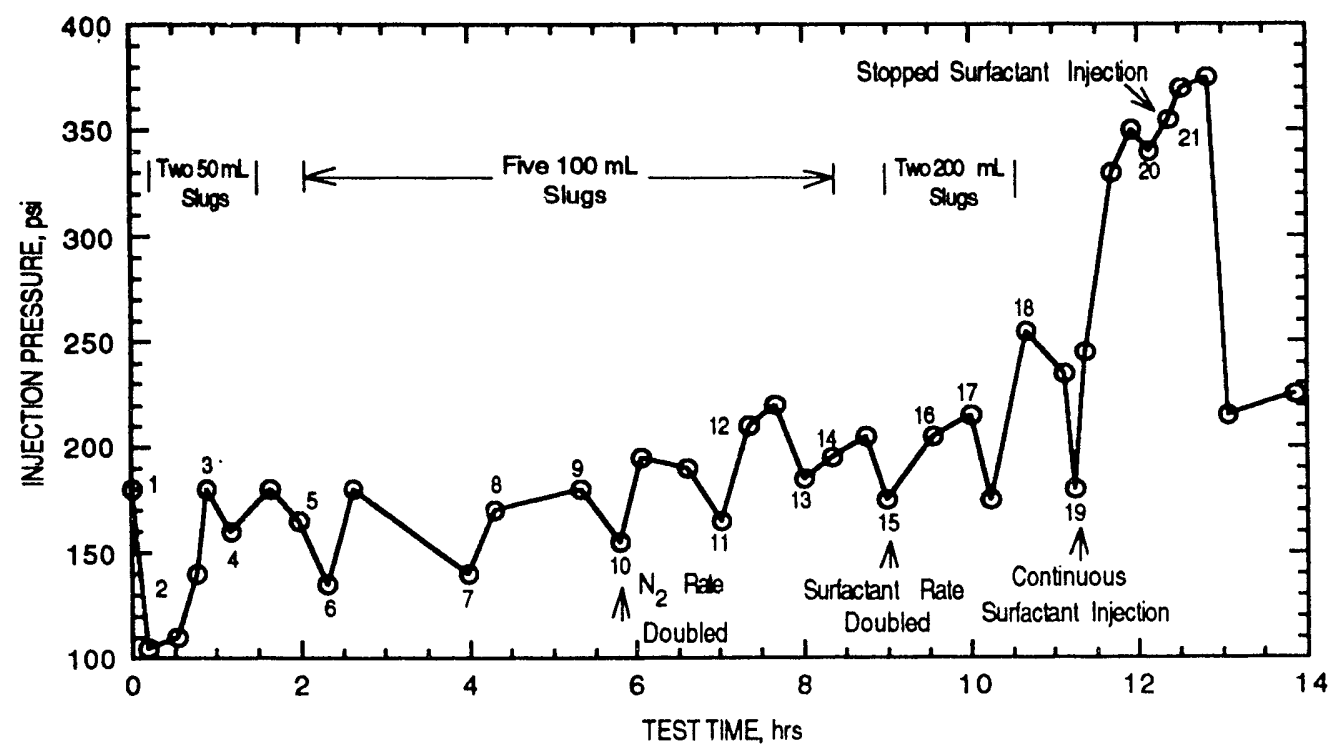

FIGURE 7. - Pressure response history from a variety of injection strategies ending with a continuous injection strategy. Steam, $\mathrm{N}_{2}$ and surfactant solution $(1 \% \mathrm{SD}-1020)$ were injected into a preheated sandpack initially saturated with water. The injection protocol is given in Table 2.

TABLE 2. - Injection protocol for figure 7

\begin{tabular}{|c|c|c|c|}
\hline $\begin{array}{l}\text { No. in } \\
\text { Eir. } 7\end{array}$ & Description & $\begin{array}{c}\text { Steam Rate } \\
\text { mUmin. (CWE) }\end{array}$ & $\begin{array}{c}\mathrm{N}_{2} \text { Rate } \\
\mathrm{mL} / \mathrm{min} \text {. (STP) }\end{array}$ \\
\hline 1 & Ist $50 \mathrm{cc}$ Foamer Slug Inj. & 0 & 0 \\
\hline 2 & No Foamer Injection & 9.42 & 100 \\
\hline 3 & 2nd $50 \mathrm{cc}$ Foamer Slug Inj. & 0 & 0 \\
\hline 4 & No Foamer Injection & 9.42 & 100 \\
\hline 5 & 1 st 100 cc Foamer Slug Inj. & 0 & 0 \\
\hline 6 & No Foamer Injection & 9.42 & 100 \\
\hline 7 & 2nd $100 \mathrm{cc}$ Foamer Slug Inj. & 9.42 & 0 \\
\hline 8 & No Foamer Injection & 9.42 & 100 \\
\hline 9 & 3rd $100 \mathrm{cc}$ Foamer Slug Inj. & 9.42 & 0 \\
\hline 10 & No Foamer Injection & 9.42 & 200 \\
\hline 11 & 4th $100 \mathrm{cc}$ Foamer Slug Inj. & 9.42 & 0 \\
\hline 12 & No Foamer Injection & 9.42 & 200 \\
\hline 13 & 5th $100 \mathrm{cc}$ Foamer Slug Inj. & 9.42 & 0 \\
\hline 14 & No Foamer Injection & 9.42 & 200 \\
\hline 15 & 1st 200 cc Foamer Slug Inj. & 9.42 & 100 \\
\hline 16 & No Foamer Injection & 9.42 & 100 \\
\hline 17 & 2nd $200 \mathrm{cc}$ Foamer Slug Inj. & 9.42 & 200 \\
\hline 18 & No Foamer Injection & 9.42 & 200 \\
\hline 19 & $\begin{array}{l}\text { Continuous Foamer Inj. } \\
\text { at a rate of } 6.2 \mathrm{ml} / \mathrm{min} \text {. }\end{array}$ & 9.42 & 200 \\
\hline $\begin{array}{l}20 \\
21\end{array}$ & $\begin{array}{l}\text { Continuous Foamer Inj. } \\
\text { No Foamer Injection }\end{array}$ & $\begin{array}{l}9.42 \\
9.42\end{array}$ & $\begin{array}{l}100 \\
100\end{array}$ \\
\hline
\end{tabular}


surfactant injection was terminated for a duration long enough to collapse the foam and for the system to stabilize. The last part of the test consisted of continuous injection of surfactant along with steam and $\mathrm{N}_{2}$, and then terminating surfactant injection to observe foam breakdown behavior.

Continuous injection developed pressures approaching that of steam saturation conditions, which were generally more than double those of the slug type injections. After stopping continuous surfactant injection, pressure continued to rise for about $30 \mathrm{~min}$. (20 psi rise), then sharply declined. During slug-type surfactant injections along with a vapor phase, the pressure drop typically rose but fell shortly after injection termination. A likely explanation is that the surfactant was washed out by the subsequent steam $/ \mathrm{N}_{2}$ injection cycles. The surfactant start/stop character of the slug type surfactant injection limited the maximum rise in pressure drop to less than that of continuous surfactant injection.

Figure 8 shows the results from another test in which injection strategies were varied. As in the previous test, surfactant, steam, and $\mathrm{N}_{2}$ rates were arbitrarily changed without any systematic order. Table 3 outlines the injection protocol for this test. In contrast to the previous test (figure 7 and table 2) in which slug type surfactant injection was employed prior to the continuous injection, the sequence was reversed. A continuous injection of surfactant and nitrogen was followed by steam injection. Two $200-\mathrm{mL}$, four $100-\mathrm{mL}$, and three $50-\mathrm{mL}$ slugs of surfactant were then periodically injected. The test was concluded by injecting surfactant/steam/ $\mathrm{N}_{2}$ continuously at varying vapor-to-liquid fractions (VLF) and steam-to- $\mathrm{N}_{2}$ ratios (SNR).

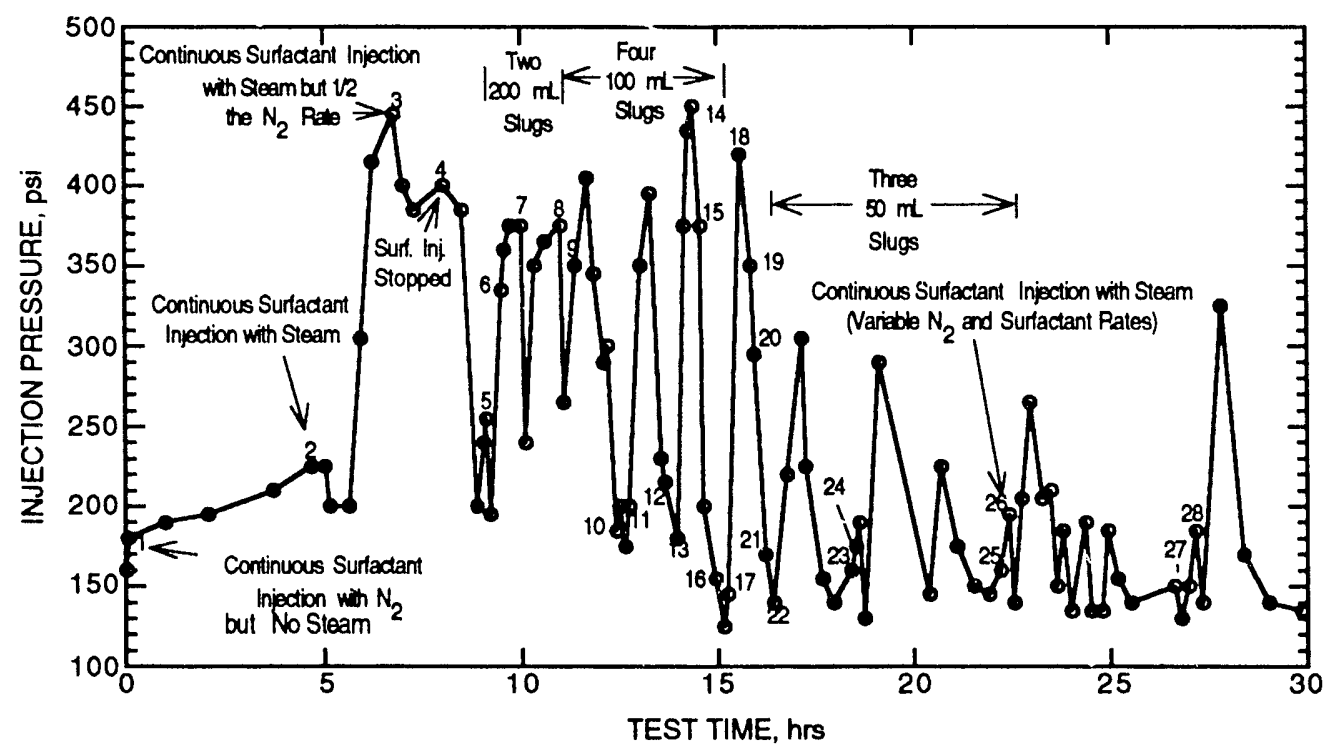

FIGURE 8. - Pressure response history from a variety of injection strategies beginning with a continuous injection strategy. Steam, $\mathrm{N}_{2}$ and surfactant solution (1\% SD-1020) were injected into a preheated sandpack initially saturated with water. The injection protocol is given in table 3 . 
TABLE 3. - Injection protocol for figure 8

\begin{tabular}{|c|c|c|c|c|}
\hline $\begin{array}{l}\text { No. in } \\
\text { Eir. } 8\end{array}$ & Description & $\begin{array}{c}\text { Steam rate } \\
\mathrm{mL} / \mathrm{min} \text { (CWE) }\end{array}$ & $\begin{array}{c}\mathrm{N}_{2} \text { Rate } \\
\mathrm{mU} / \min \text { (SIP) }\end{array}$ & $\begin{array}{r}\text { Foaner rate } \\
\mathrm{mL} / \mathrm{min} .\end{array}$ \\
\hline 1 & No Steam & 0 & 200 & 5.52 \\
\hline 2 & Continuous Foamer Inj. & 9.42 & 200 & 3.33 \\
\hline 3 & Continuous Foamer Inj. & 9.42 & 100 & 3.33 \\
\hline 4 & No Foamer Inj. & 9.42 & 100 & 0 \\
\hline 5 & 1st 200 cc Foamer Slug Inj. & 9.42 & 100 & 5.52 \\
\hline 6 & No Foamer Inj. & 9.42 & 100 & 0 \\
\hline 7 & 2nd $200 \mathrm{cc}$ Foamer Slug Inj. & 9.42 & 200 & 5.52 \\
\hline 8 & 1 st 100 cc Foamer Slug Inj. & 9.42 & 0 & 5.52 \\
\hline 9 & No Foamer Inj. & 9.42 & 100 & 0 \\
\hline 10 & 2nd $100 \mathrm{cc}$ Foamer Slug Inj. & 9.42 & 0 & 5.52 \\
\hline 11 & No Foamer Inj. & 9.42 & 100 & 0 \\
\hline 12 & 3rd 100 cc Foamer Slug Inj. & 9.42 & 0 & 5.52 \\
\hline 13 & No Foamer Inj. & 9.42 & 200 & 0 \\
\hline 14 & No Foamer Inj. & 9.42 & 100 & 0 \\
\hline 15 & No Foamer Inj. & 9.42 & 200 & 0 \\
\hline 16 & 4th $100 \mathrm{cc}$ Foamer Slug Inj. & 9.42 & 0 & 5.52 \\
\hline 17 & No Foamer Inj. & 9.42 & 200 & 0 \\
\hline 18 & No Foamer Inj. & 9.42 & 100 & 0 \\
\hline 19 & No Foamer Inj. & 9.42 & 150 & 0 \\
\hline 20 & No Foamer Inj. & 9.42 & 200 & 0 \\
\hline 21 & 1st 50 cc Foamer Slug Inj. & 9.42 & 0 & 5.52 \\
\hline 22 & No Foamer Inj. & 9.42 & 100 & 0 \\
\hline 23 & 2nd $50 \mathrm{cc}$ Foamer Slug Inj. & 9.42 & 0 & 6.1 \\
\hline 24 & No Foamer Inj. & 9.42 & 100 & 0 \\
\hline 25 & 3rd $50 \mathrm{cc}$ Foamer Slug Inj. & 9.42 & 0 & 6.1 \\
\hline 26 & Continuous Foamer Inj. & 9.42 & 100 & 5.25 \\
\hline 27 & Continuous Foamer Ini. & 9,42 & 0 & 5.25 \\
\hline
\end{tabular}

The continuous injection of surfactant along with $\mathrm{N}_{2}$ and steam was again found to be effective in quickly building up pressures to a peak. The earlier part of continuous surfactant injection with $\mathrm{N}_{2}$ but without steam showed a very small pressure increase due to a very low VLF. Each of the two 200-mL surfactant slugs injected later were able to regain most of the pressure drop, even though momentarily. Each of the following four $100-\mathrm{mL}$ ( $20 \% \mathrm{PV}$ ) slugs showed the best performance observed for the slug type injection in this test. The effective average pressure might have been somewhat lower than the peak pressure because of fluctuations, but it compared favorably with the concurrent injection scheme because of substantially lower surfactant consumption. The three $50-\mathrm{mL}$ slugs were not nearly as effective in building pressure as the previous large: slugs-probably due to a higher impact of the surfactant wash out discussed earlier.

These test results show that the continuous injection of surfactant with a gas phase is more effective in buiiding up pressure than a slug type injection. A combination of continuous injection followed by slug type injection seems to be a viable method. The best performance in a slug type injection that follows after a continuous injection is seen when surfactant slugs of $20 \%$ of PV are periodically injected along with steam and $\mathrm{N}_{2}$.

Continuous injection of surfactant was resumed before the conclusion of the test, with a constant steam rate but variable $\mathrm{N}_{2}$ and surfactant solution rates. The failure to build up pressure 
nearly as much as in the earlier continuous injection (starting at point 2) is attributed to a lower $\mathrm{N}_{2}$ rate (i.e. half). This is also supported by the observation at point 3 , where the pressure fell significantly as $\mathrm{N}_{2}$ rate was reduced (halved) while other rates were kept constant. Changes in the surfactant injection rate, which also changed the VLF, had only a moderate influence in comparison to $\mathrm{N}_{2}$ rate changes.

\section{Effect of Vapor-to-Liquid Fraction (VLF)}

Figure 9 shows the relationship between VLF and the maximum pressure drop attained in a test. The figure shows the VLF to be a critical parameter for onset and stability of foam. When liquid contents are too low, sufficient surfactant is not available to compensate for adsorption, dilution, depletion, and possibly other losses. When liquid contents are two high, the mixture behaves like a gas-in-water dispersion and loses many of the characteristics of foam. A VLF of 423 - the highest tested - gave the best performance (during continuous steam/ $\mathrm{N}_{2} /$ surfactant injection) compared to VLF's of 5, 8, 266, and 316.

VLF may be the reason that slug type injection was not as effective as continuous injection. However, the pressure drop with $100-\mathrm{mL}$ slugs ( $20 \% \mathrm{PV}$ ) injected after a continuous injection was reasonably close to that from continuous injection. The 200 - and $50-\mathrm{mL}$ surfactant slugs showed inferior performance. Maintaining a desirable VLF during slug type injection is difficult because of frequent changes in the contents of injected fluids. Slug type injection offers one advantage over continuous injection, i.e., a prior knowledge of correct VLF is not as important. The correct VLF is likely to exist sometime during the injection, albeit briefly, because of rapidly changing saturation distributions. This characteristic may be important for reservoir applications because the length of a fixed-volume slug is reduced as it moves radially away from the injection well.

\section{Effect of Injection Rate}

The effect of steam injection-rate changes on foaming behavior is shown in figure 10 , which shows that the fluid injection rates affected both the onset of foaming and the maximum pressure drop. The injection rate of each fluid was changed proportionally in these tests (as shown in the figure) to maintain the fixed rate ratios. These fixed rate ratios were selected on the basis of optimum foaming performance within the specified range of experimental equipment. Each cycle consisted of a concurrent injection of steam, $\mathrm{N}_{2}$ and surfactant until the peak pressure was attained (pressure buildup), and then terminating surfactant injection while steam and $\mathrm{N}_{2}$ flowed continuously at constant rates (pressure decay). Consequently, the total flow rate during the pressure decay part of each cycle was reduced because of surfactant shut-down. 


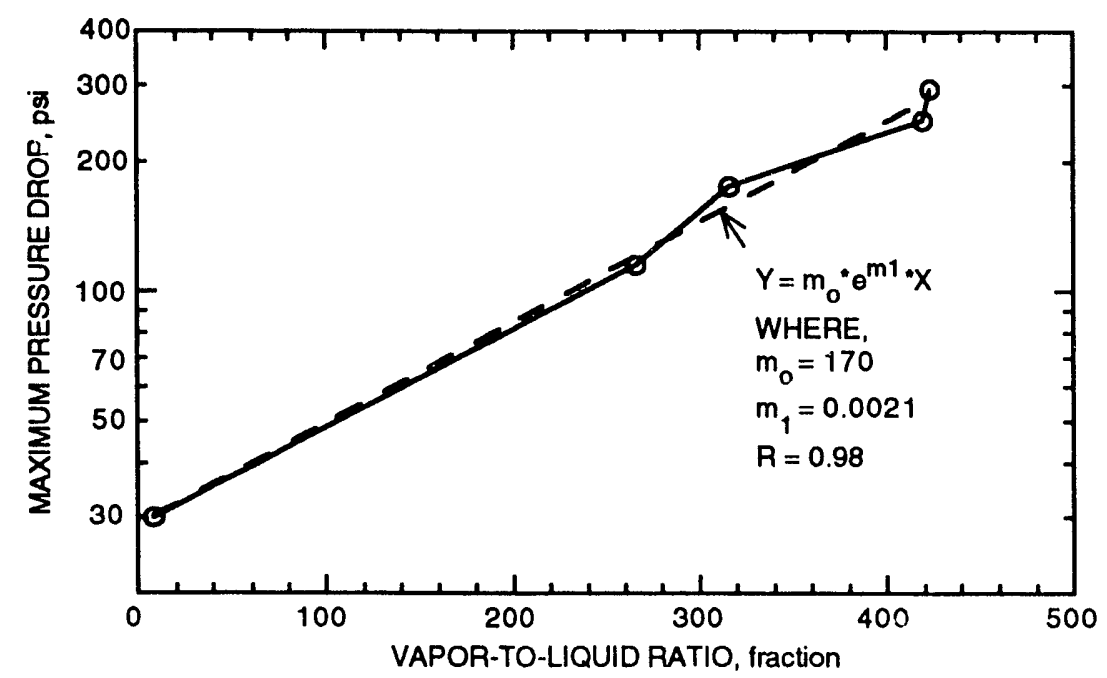

FIGURE 9. - Maximal pressure drop attainment in relation to the vapor contents of the injected fluids. Steam, $\mathrm{N}_{2}$ and surfactant solution (1\% SD-1020) were injected at arbitrary rates into a preheated sandpack initially saturated with water.

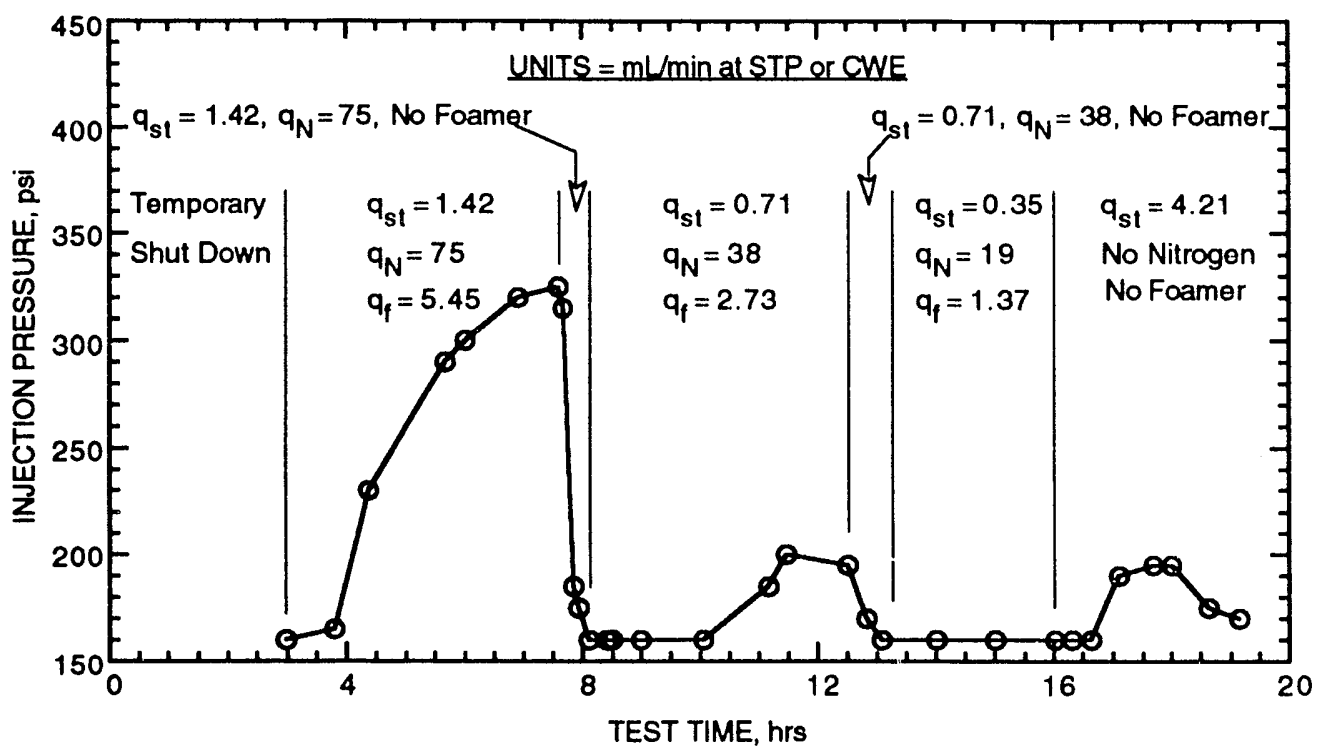

FIGURE 10. - Pressure response history during a test in which the injection rates of steam, $\mathrm{N}_{2}$ and surfactant solution (1\% SD-1020) were reduced stepwise in a proportion that maintained the same rate ratios. The sandpack was preheated and initially saturated with water. 
A log-linear relationship was observed between the delay in onset of foaming and the steam injection rate when the rate ratios were kept unchanged (figure 11), with higher rates propagating foam earlier. The effect of injection rate on the maximum pressure drop was also significant, especially near the optimal conditions. Optimal conditions are arbitrarily defined to be the lowest steam, $\mathrm{N}_{2}$ and surfactant-solution injection rates (at suitable rate-ratios) sufficient to increase the injection pressure to the steam saturation pressure. A plot of maximum pressure drop vs. rate, while maintaining a fixed rate-ratio is shown in figure 12 . Both figures 11 and 12 contain data from tests reported in figure 10 as well as other tests. Based on figures 10 through 13, it can be inferred that the fluid rate changes affect the foaming performance within a certain range (tenfold change for 1\% SD-1020). A log-linear relationship exists between the delay in onset of foaming and fixed-proportion total fluid rate changes within the range of influence.

\section{Effect of the Noncondensible Gas Fraction}

A test was performed to analyze the role of the noncondensible gas in which steam $/ \mathrm{N}_{2} /$ surfactant solution were injected simultaneously for the entire experiment. Steam (CWE) and surfactant solution rates were kept constant, while the $\mathrm{N}_{2}$ rate was reduced in steps of 55, 28 , and $19 \%$ of the initial $\mathrm{N}_{2}$ rate.

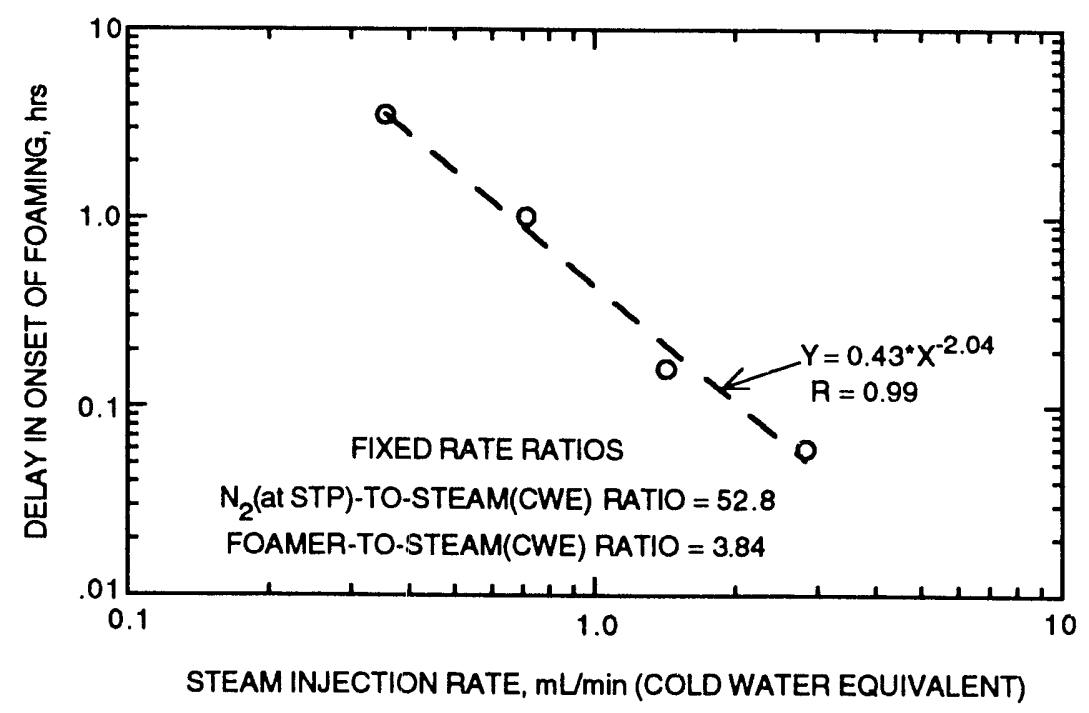

FIGURE 11. - Delay in onset of foaming in a oil-free, preheated sandpack in relation to fluid injection rates. Steam, $N_{2}$ and surfactant solution (1\% SD-1020) rates were also changed to maintain the optimum rate ratios. 


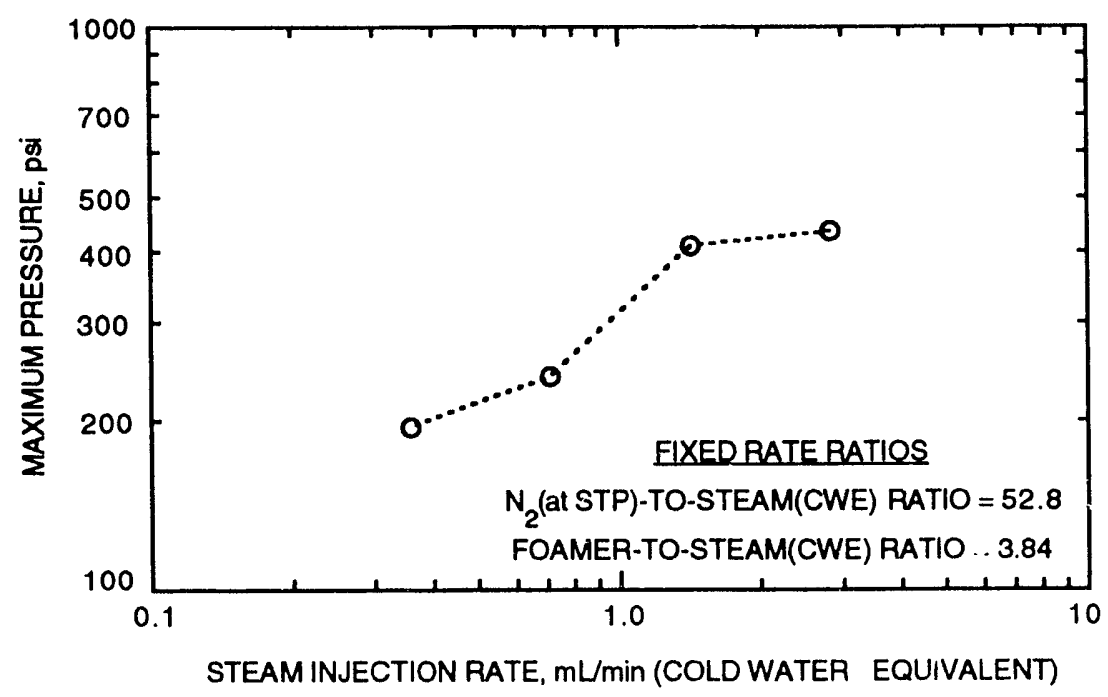

FIGURE 12. - Maximal pressure drop in an oil-free, preheated sandpack with variable fluid injection rates. Steam, $N_{2}$ and surfactant solution (1\% SD-1020) rates were changed to maintain the optimum rate ratios.

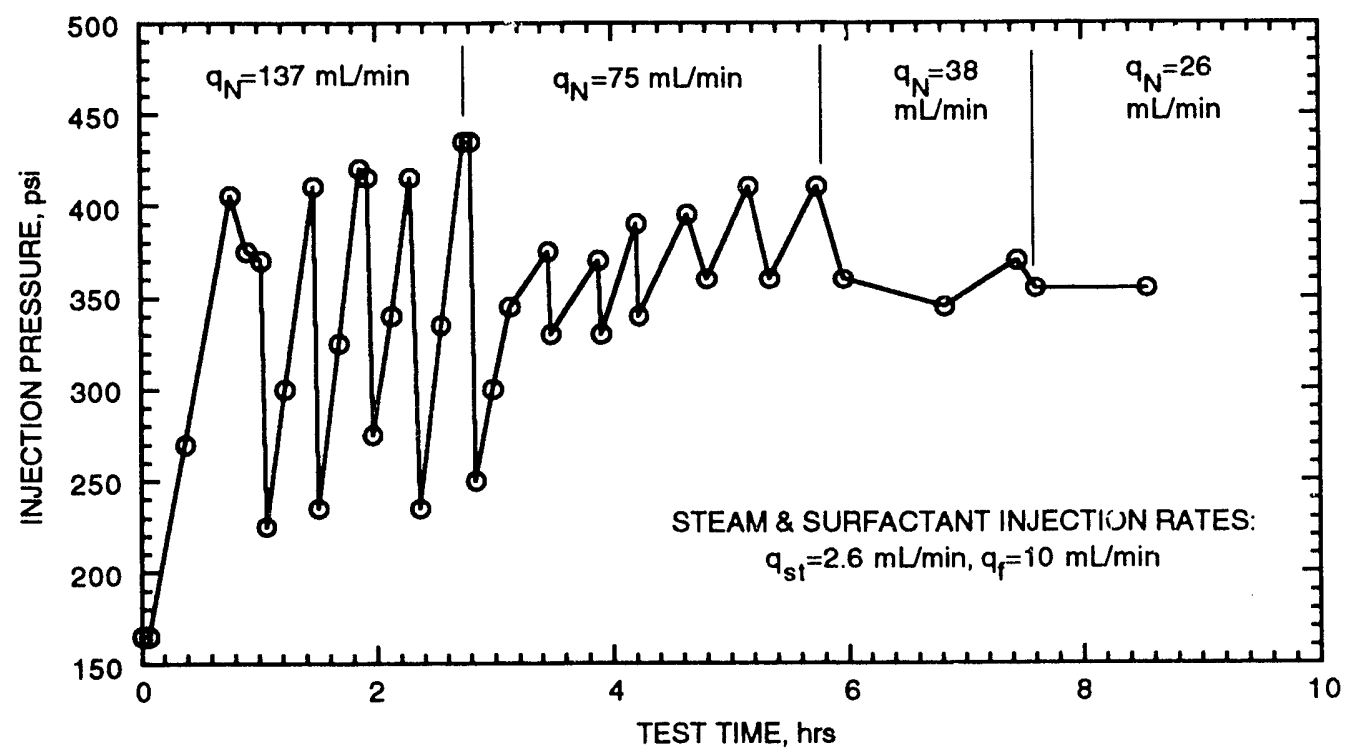

FIGURE 13. - Pressure response history with stepwise reduction of non-condensible gas $\left(\mathrm{N}_{2}\right)$ rate. Steam and surfactant solution $(1 \%$ SD-1020) rates were unchanged. The sandpack was preheated and initially saturated with water. 
Test results are shown in figure 13. A decrease in the $\mathbf{N}_{2}$ fraction in the injectants reduced the peak injection pressure. Smaller fluctuations in the pressure wers enco'sntered as the $\mathrm{N}_{2}$ rate was decreased. A definite explaration for the higher fluctuations at higher $\mathrm{N}_{2}$ fractions is not known; a likely one is that it was caused by increased foaming.

In this test, the VLF was lowered as a consequence of the stepwise decrease in the $\mathrm{N}_{2}$ injection rate since other injection rates remained constant. This lowering of VLF might have been partially responsible for the reduction in foaming. However, the $\mathrm{N}_{2}$ in these tests contributed only 1 to $5 \%$ to the vapor ?hase (see figure 14, qsteam / qnitrogen $\geq 20$ ); hence, the associated change in VLF was too small to be of any consequence.

These results are in agreement with those of previous studies showing a strengthening of foam resulting from the injection of even small volumes of a noncondensible gas ${ }^{36}$ and a significant increase in pressure drop with an increase in the injection rate of noncondensible gas $\left(\mathrm{N}_{2}\right) .{ }^{39}$ The results also show an almost linear relationship (figure 14) between the ste um-tonitrogen ratio, SNR (in situ) and the maximum pressure drop observed with a sixfold variation in SNR.

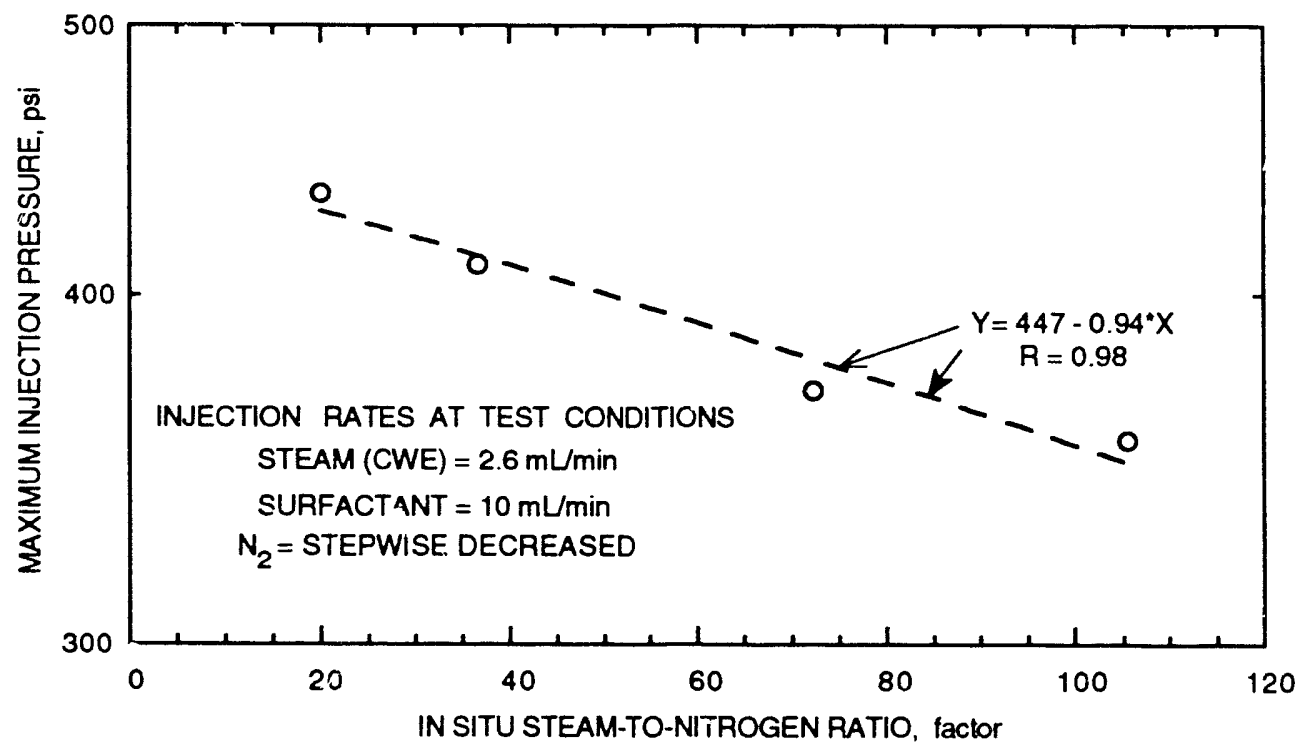

FIGURE 14. - Maximal injection pressure attainment in relation to the non-condensible gas $\left(\mathrm{N}_{2}\right)$ fraction. Steam, $N_{2}$, and surfactant solution (1\% SD-1020) were injected into a preheated sandpack initially saturated with water. 


\section{Role of BPR Performance}

A microprocessor-based electronic BPR (E-BPR) was recently installed in our 1-D sandpack experimental system. It is highly effective in controlling the backpressure within a few psi and its use eliminates pressure fluctuations in the sandpack. The existing mechanical BPR (M-BPR), on the other hand, shows significant pressure fluctuations during steam-foam processes. With this new addition of the high-precision E-BPR, it was deemed important to compare its performance with the older one, because the higher fluctuations encountered with the M-BPR allowed erratic fluid flow during the periodic openings. Such information is not only important for validating our earlier data, but is useful also in comparing the studies using different BPRs.

Figures 15 and 16 compare foaming performance with the two different backpressure regulators. Figure 15 shows a test which started with the E-BPR. When the pressure stabilized at $240 \mathrm{psi}$, the backpressure regulator was switched from the E-BPR to the M-BPR. This switch in BPR did not cause any significant change in pressure response for about 5 hours. In the second half of the test, the BPR was switched back to the E-BPR, which led to a big jump in pressure.

The test shown in figure 16 was performed at higher steam and nitrogen rates, but a lower surfactant rate. In contrast to the previous test, the M-BPR was used first to initially generate foam. When the pressure climbed and stabilized at $360 \mathrm{psi}$, the BPR was switched from the M-BPR to the E-BPR. It raised the pressure further to $400 \mathrm{psi}$, at which point, surfactant injection was stopped. A second cycle of pressure buildup/decay was carried out using the E-BPR and attained a slightly higher oressure ( $425 \mathrm{psi}$ ) then previous cycle that started with the M-BPR.

Admittedly, the comparison of BPRs in the manner-switching back and forth-can raise many questions. A simple comparison of two tests, one with each BPR, would have been inadequate for the dual objectives of observing the ability of each BPR to generate as well as sustain foam. Nevertheless, the results in these two figures clearly suggest that somewhat higher pressures can be attained with E-BPR. Further tests will be made to confirm this observation.

\section{Other Related Observations}

These results support the literature in showing that the foam flooding performance is very much system dependent in a way which is still not adequately understood. Requirements for the onset of foam generation, rate dependency of foaming behavior, and interaction with oils of varying types are some important observations not adequately explained by the literature or this study.

A long delay was always observed between the beginning of the surfactant injection and initial foam generation in every test. The frontal behavior of foam propagation was difficult to describe with any certainty. A possible explanation consistent with our observations is presented in figure 17. 


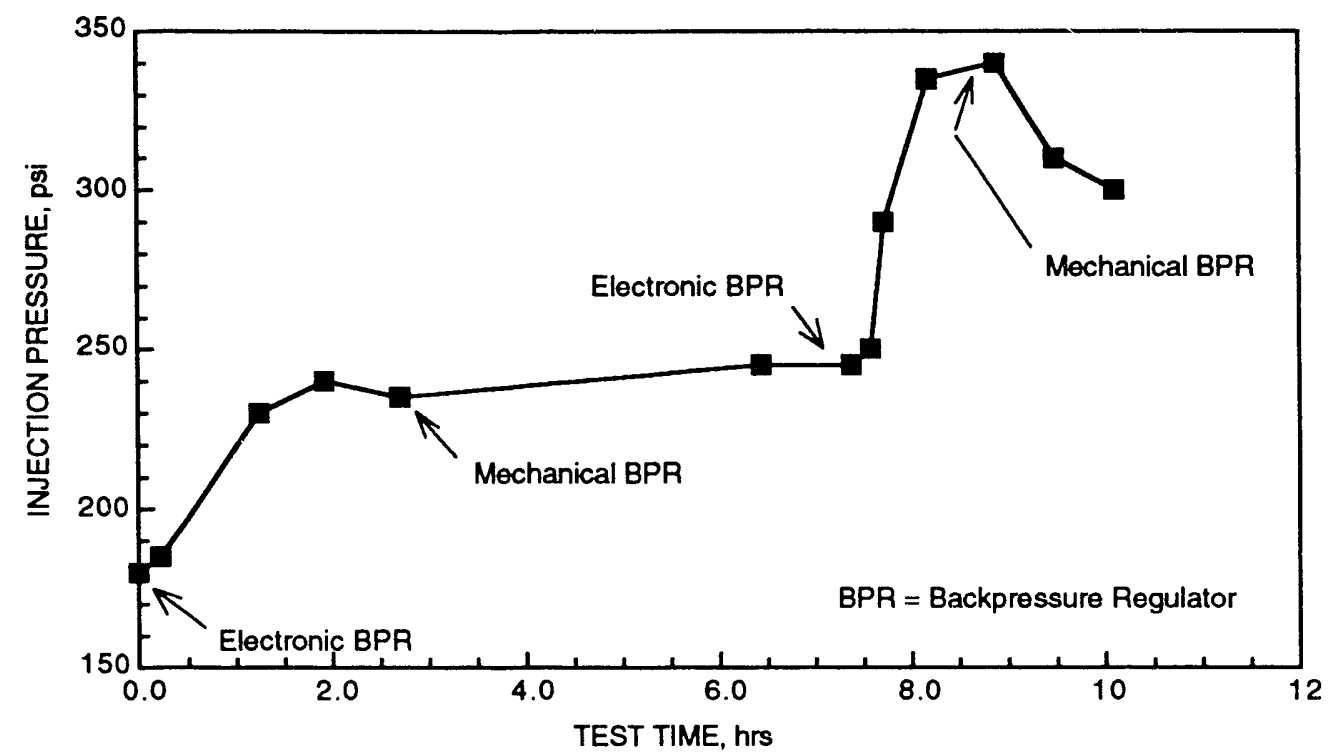

FTGURE 15. - Pressure response with two different backpressure regulators during concurrent steam, $\mathrm{N}_{2}$, and surfactant solution (1\% SD-1020) injection into a preheated sandpack.

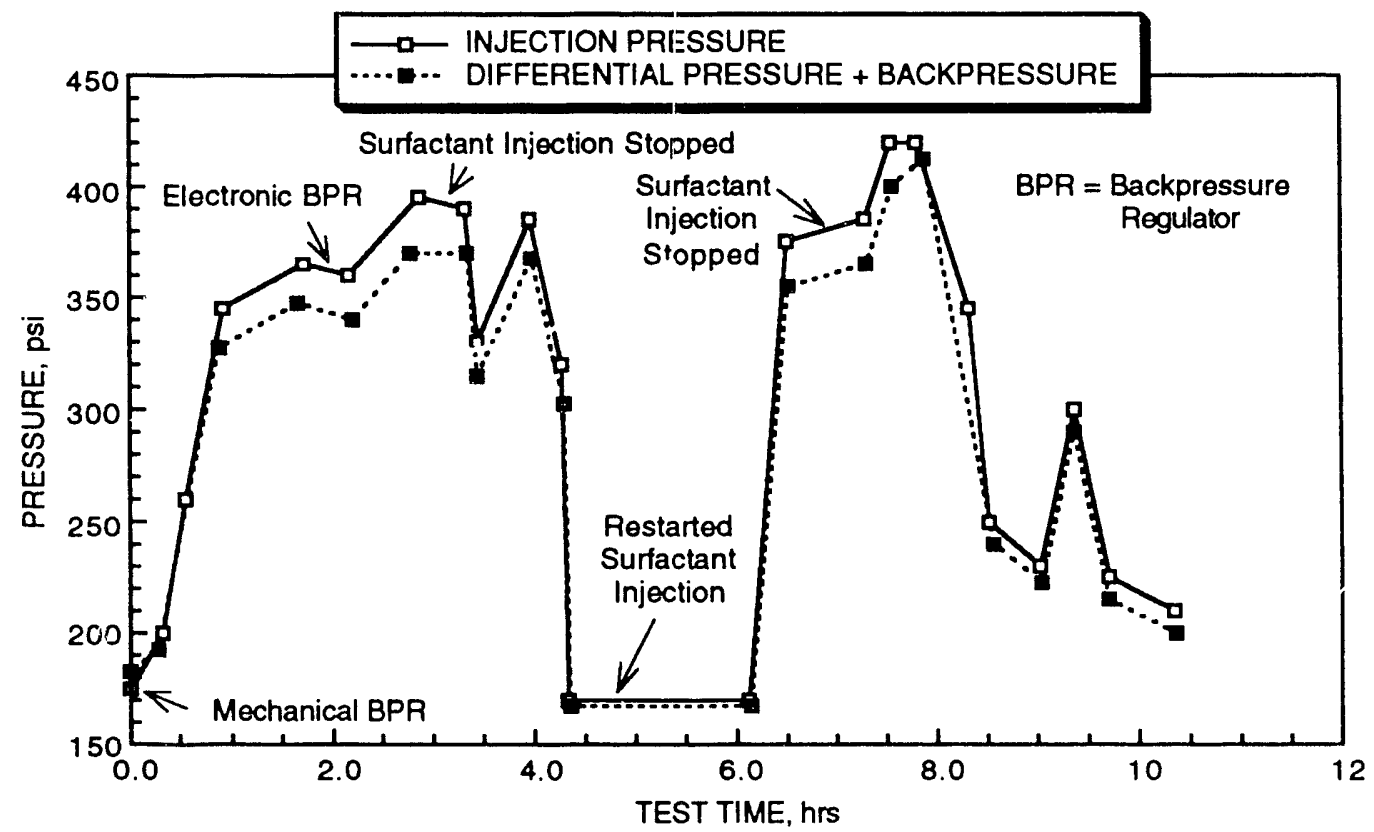

FIGURE 16. - Pressure response with two different backpressure regulators during concurrent steam, $\mathrm{N}_{2}$, and surfactant solution (1\% SD-1020) injection into a preheated sandpack. 


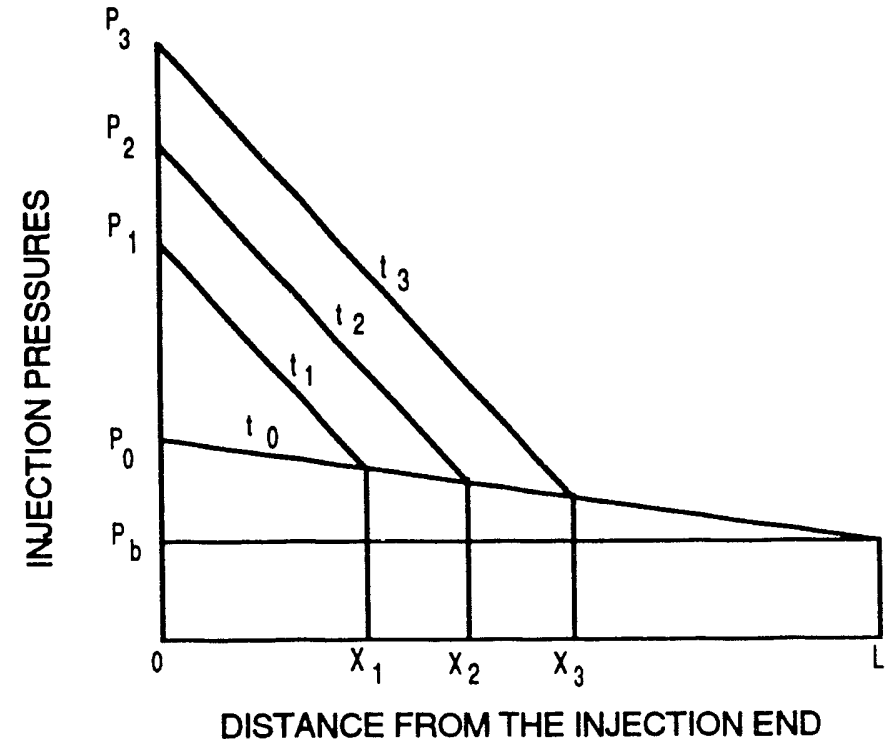

(a)

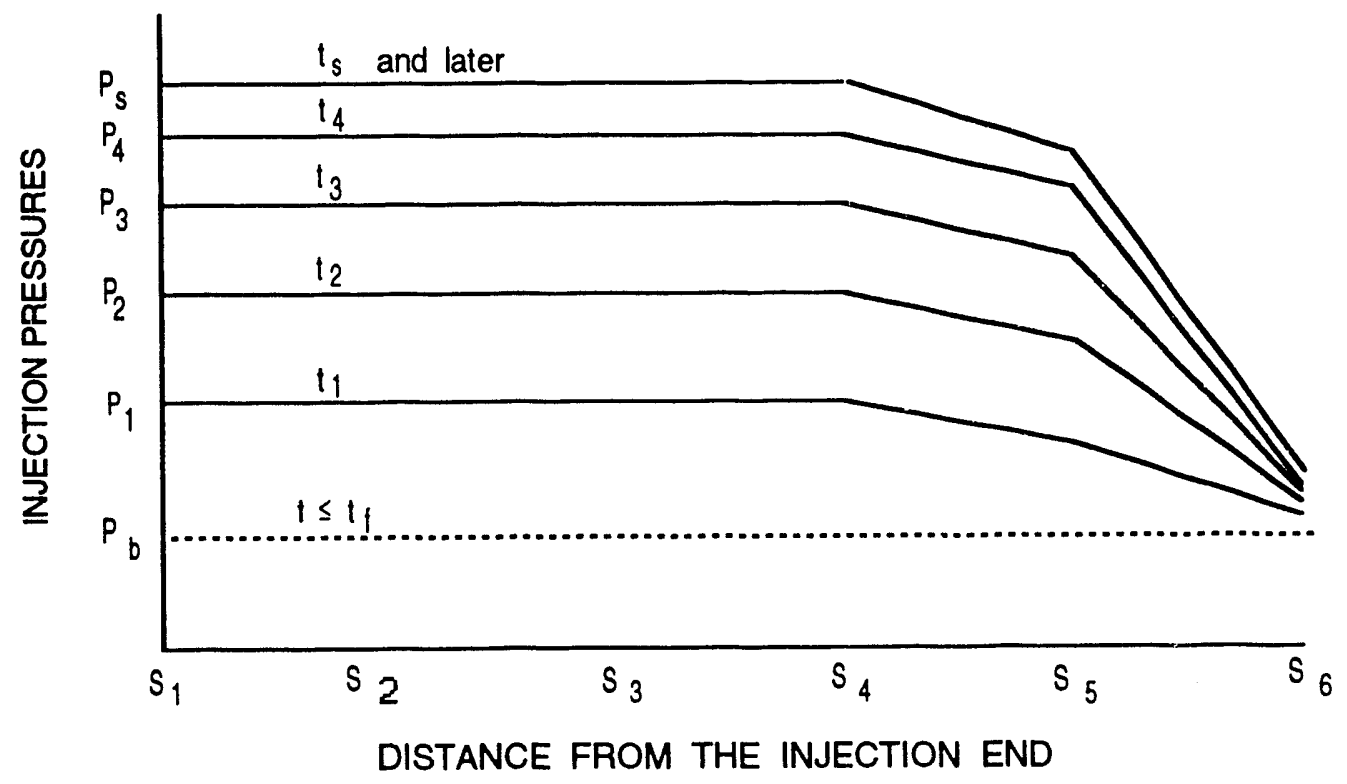

(b)

FIGURE 17. - An outline of pressure distributions: (a) Expected profiles during a constant rate advancement of a lower mobility fluid, (b) Observed profiles during steam-foam displacement experiments. 
Figure 17(a) show's the expected pressure distribution during a displacement in which a lower mobility fluid is advancing at constant injection rate toward the producing end. The injection pressure continues to climb until the front reaches the producing end. The actual pressure distribution observed in steam-foam tests is shown in figure 17(b), which is quite different from that of figure 17(a). Even though the total pressure drop is changing in the early stages, it appears to be more or less uniform in the first four sensor locations at any given time. The last two sensors show sharp pressure changes with the last having the steepest slope. This implies that the maximum resistance to flow occurs near the producing end, perhaps because of higher velocities and/or higher vapor-to-liquid ratio there. It also suggests that there is a cap on the maximum pressure rise, since the pressure did not increase beyond the steam saturation pressure.

Most of the repeated tests were in qualitative agreement with each other. However, some oilcontaining tests encountered repeatability problems; for example, similar tests were sometimes in disagreement by as much as $25 \%$ in the onset of foaming and $6 \%$ in the maximum pressure drops. This discrepancy was due to the inherent difficulties in attaining identical initial oil saturation in the repeated tests and the poor performance of the mechanical backpressure regulator (M-BPR) during three-phase flow. A few tests yielded ambiguous results, which were discarded on the basis of known operational problems such as improper temperature control, dysfunctional M-BPR, or inaccurate oil saturation determinations.

Despite continuous extenal heating, the temperature in the last 1 in. of sandpack (near the production end) remained close to $360^{\circ} \mathrm{F}$. A probable explanation is the sharp pressure drop at the exit end causing the re-evaporation of condensed water. This process, requiring latent heat, lowers and maintains the temperature at the saturation temperature level corresponding to the backpressure setting $\left(360^{\circ} \mathrm{F}\right.$ at $\left.153 \mathrm{psi}\right)$.

Foam under dynamic conditions collapsed soon after the injection of surfactant was terminated in most tests. Foaming was maintained only with continuous injection, or with frequent injection of small slugs of surfactant. One experiment suggested that foam stability was significantly higher in a static condition. In the test shown in figure 18 , several pore volumes of steam and $\mathrm{N}_{2}$ were initially injected. When flow stabilized, surfactant injection began along with the steam and $\mathrm{N}_{2}$. After the pressure drop rose significantly due to foam generation, all three injections were terminated. Steam and $\mathrm{N}_{2}$ were then restarted without surfactant after more than two hours. The same higher pressure drop was observed instantaneously as at the time of flow termination, perhaps because of pre-existing foam. 


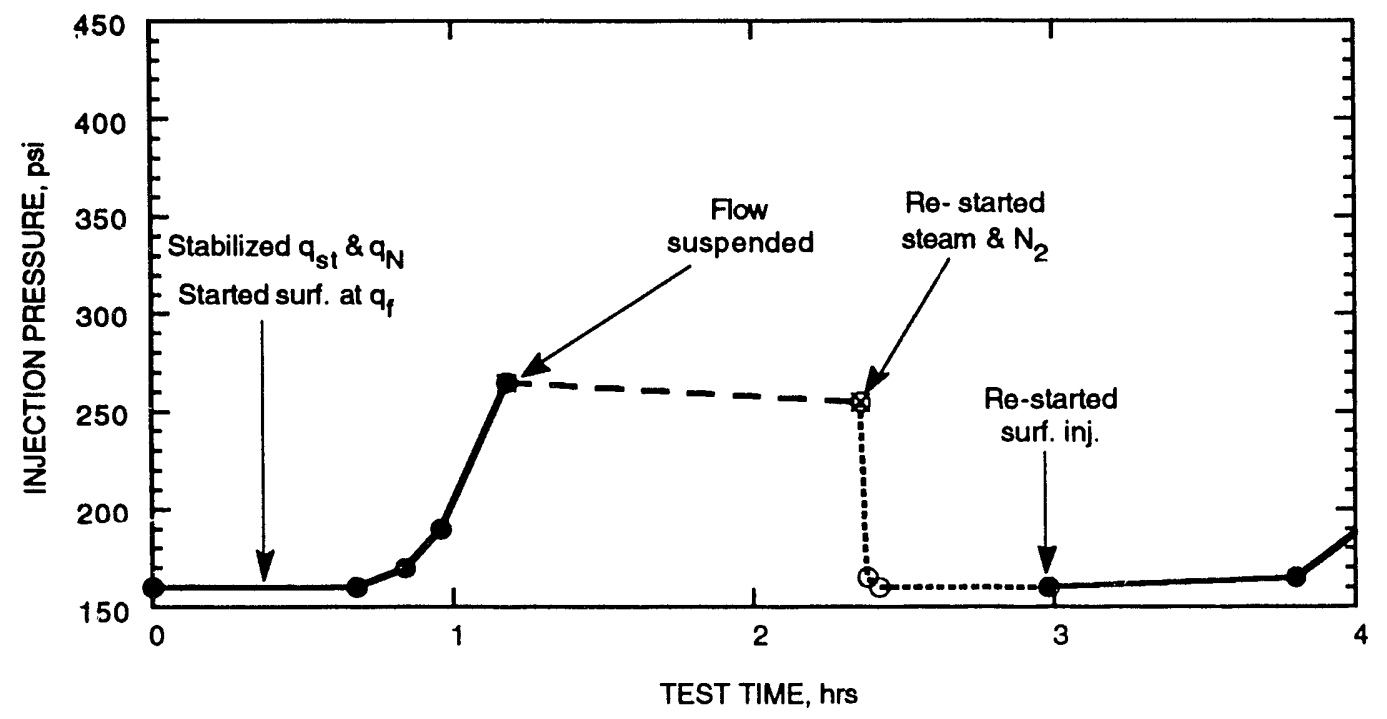

FIGURE 18. - Time versus pressure plot showing foam stability in a static condition.

\section{OBSERVATIONS AND CONCLUSIONS}

From the experimental results of steam/surfactant/additive mobility tests performed under linear, horizontal, and isothermal conditions, the following observations and conclusions can be inferred.

1. Chevron's $1 \%$ Chaser SD-1020 and Shell's $1 \%$ LTS-18, when injected concurrently with steam and $\mathrm{N}_{2}$ into a pre-heated water-saturated sandpack, are both effective in reducing the gas-phase mobility to a point where injection pressure reaches the steam saturation pressure.

2. Both surfactants have a moderate tolerance to salt. Addition of about $1 \%$ sodium salts (chloride, carbonate or bicarbonate) to the two surfactant solutions only slightly lowers the response and only slightly impairs mobility reduction characteristics relative to the no-salt conditions. A higher concentration of salt $(5 \% \mathrm{NaCl})$ can precipitate a surfactant solution (1\% SD-1020) to the extent that it fails to show any pressure response.

3. The peak foaming performance in the three oils tested was the same as that in oil-free tests. However, the onset of foaming and rate of pressure rise were different, presumably because of differences in emulsifiability and steam induced microscopic sweep efficiency. 
4. Continuous injection of surfactant with the gas phase is more effective in building up pressure than a slug type injection. A combination of continuous injection followed by slug type injection seems to be a viable method. The best performance in a slug type injection that followed a continuous injection is seen when surfactant slugs of $20 \%$ of the PV are periodically injected along with steam and $\mathrm{N}_{2}$.

5. The vapor-liquid fraction (VLF) is a critical parameter for onset and stability of foam. A VLF of 423, the highest tested, gave the best performance.

6. Fluid rate changes affect the foaming performance within a certain range (tenfold change for $1 \%$ SD-1020). A log-linear relationship exists between the delay in onset of foaming and fixed-proportion total fluid rate changes within the range of influence.

7. An almost linear relationship was observed between the steam-to-nitrogen ratio, SNR (in situ) and the maximum pressure drop attained over a sixfold variation in SNR. Within this range, an increase in $\mathrm{N}_{2}$ contents raised the maximum pressure drop due to increased foaming.

8. The electronic backpressure regulator is able to attain somewhat higher pressures than the mechanical BPR.

9. An increase in the injection pressure above saturation causes steam condensation resulting in a reduction of VLF and a corresponding collapse of foam. Thus, the maximum pressure rise due to foaming is limited by steam saturation conditions.

\section{ACKNOWLEDGMENTS}

This work was sponsored by the U.S. Department of Energy under cooperative agreement DE-FC22-83FE60149. The authors wish to thank Yesh Tyagi for preparation of some figures and Paul Stapp, M. K. Tham, A. Strycker, P. S. Sarathi of NIPER; and T. B. Reid of DOE Bartlesville Project Office for their critical reviews. The authors wish to thank Chevron Chemical and Shell Chemical companies for supplying surfactants.

\section{REFERENCES}

1. Volek, C. W. and J. A. Pryor. Steam Distillation Drive-Berea Field, Califomia. J. Pet. Tech. (Aug. 1972), 8y9-906.

2. Konopnicki, D. T. et al. Design and Evaluation of the Shields Canyon Field Steam-Distillation Drive Pilot Project, J. Pet. Tech. (May 1979) 546-552.

3. Chappelle, H. H., G. P. Emsurak Jr., and S. L. Obernyer, S. L. Screening and Evaluation of Enhanced Oil Recovery at Teapot Dome in the Shannon Sandstone, A Shallow Heterogeneous Light Oil Reservoir. Paper SPE/DOE 14918 presented at the SPE/DOE Fifth Symposium on Enhanced Oil Recovery, Tulsa, OK, Apr. 20-23, 1986.

4. Gangle, F. J., G. V. Weyland, J. P. Lassiter, and E. J. Veith. Light Oil Steamdrive Pilot Test at NPR-1, Elk Hills, California. SPE 20032. Proceedings of the 60th SPE California Regional Meeting. Bakersfield, Apr. 5-7, 1990, pp. 177-185.

5. Wu, C. H. and A. Brown. A Laboratory Study on Steam Distillation in Porous Media, Paper SPE 5569 presented at the 1975 SPE Annual Fall Technical Conference and Exhibition, Dallas, Sept. 28-Oct. 1, 1975. 
6. Wu, C. H. and R. B. Elder. Correlation of Crude Oil Steam Distillation Yields With Basic Crude Oil Properties, Soc. of Pet. Eng. J (Dec. 1983) 937-945.

7. Duerksen, J. H. and L. Hsueh. Steam Distillation of Crude Oils, Soc. Pet Eng. J (April 1983) 265-271.

8. Ozen, A. S. and S. M. Farouq-Ali. An Investigation of the Recovery of the Bradford Crude by Steam Injection, J. Pet. Tech. (June 1969) 692-698.

9. Flock, D. L. and J. Lee. An Experimental Investigation of Steam Displacement of a Medium Gravity Crude Oil. The Oil Sands of Canada-Venezuela-1977. CIM Special Volume No. 17, Ed. Redford, D. A. and Winestock, A. G. The Canadian Institute of Mining and Metallurgy, Montreal, Quebec H3A 2M8 Canada, pp. 386-394.

10. Crichlow, H. B. et al. Maximizing Steam Drive Recovery in Light Oil Reservoirs. Final Report, DOE/BC/10316-26, 1983.

11. Cheung, Y. L., A. Brown and W. S. Huang. A Laboratory Study of the Tapered-Quality Steam-Water Process on Light Oil. Paper SPE 12005 presented at the 58th SPE Annual Fall Technical Conference and Exhibition, San Francisco, CA, Oct. 5-8, 1983.

12. Madden, M. P. and P. Sarathi. Light Oil Steamflooding -Core Flood Experiments. Topical Report, DOE/NIPER-44, 1985.

13. Strycker, A. and P. Sarathi. Steamflooding Light Crude Oil Reservoirs - A State-of-the-Art Review. Topical Report, DOE/NIPER-338, 1988.

14. Sarathi, P., S. D. Roark and A. Strycker. "Two-Dimensional Steamflood Laboratory Studies of Light Crude Oil Saturated Sandpack-Comparison of Waterflooded with Nonwaterflooded Porous Media." Paper presented at the 3rd International Symposium on Enhanced Oil Recovery, Maracaibo, Venezuela, Feb. 19-22, 1989.

15. Hsueh, L., K. C. Hong and J. H. Duerksen. Simulation of High Pressure and High Temperature Steam Distillation of Crude Oils. Paper UNITAR/CF 10/VIII/2 presented at the Second Int'l. Conference on Heavy Crude and Tar Sands, Caracas, Venezuela. Feb. 7-17, 1982.

16. Coats, K. H. Simulation of Steamflooding With Distillation and Solution Gas. Soc. Pet. Eng. J (Oct. 1976) 235-247.

17. Ferrer, J. and S. M. Farouq-Ali. A Three Phase, Two Dimensional Compositional Thermal Simulator for Steam Injection Processes. J. Cdn. Pet. Tech. (Jan.-March 1977) 78-90.

18. Rhee, S. W. and T. M. Doscher. A Method for Predicting Oil Recovery by Steamflooding Including the Effects of Distillation and Gravity Override. Soc. Pet. Eng. J (Aug. 1980) 249-266.

19. Aydelotte, S. R. and A. B. Ramesh. Economic Feasibility of Steam Drive in Light Oil Reservoirs. Final Report, DOE/BC/00044-1, Sept. 1979.

20. Hanzlik, E. J. Steamflooding as an Altemative EOR Process for Light Oil Reservoirs. Paper SPE 10319 presented at the 56th Annual Fall Technical Conference and Exhibition, San Antonio, TX, Oct. 5-7, 1981.

21. Hong, K. C. and J. W. Ault. Effects of Noncondensible Gas Injection on Oil Recovery by Steamflooding. J. Pet. Tech. (Dec. 1984) $2160-2170$.

22. Hong, K. C. Numerical Simulation of Light Oil Steamflooding in the Buena Vista Hills Field, California. Paper SPE 1'104 presented at the SPE 1986 International Meeting on Petroleum Engineering, Beijing, China, March 17-20, 1986.

23. Chu, C. A Comprehensive Simulation Study of Steamflooding Light Oil Reservoirs After Waterflood. J. Pet. Tech. (Jul!' 1988) 894-904.

24. Moritis, Guntus. $\mathrm{CO}_{2}$ and $\mathrm{HC}$ Injection Lead EOR Production Increase. Oil \& Gas J., Apr. 23, 1990.

25. Friedman, F. Steam Foam Mechanistic Field Trial in the Midway-Sunset Field. SPE 21780. Proceedings of the SPE Western Regional Meeting, Long Beach, California, Mar. 20-22, 1991, pp. 301-316.

26. Sarathi, P., S. Roark and A. Strycker. Light Oil Steamflooding: A Laboratory Study. Paper pres. at the SPE California Regional Meeting held in Long Beach, California, March 23-25, 1988.

27. Eson, R.L. and R.W. Cooke. A Comprehensive Analysis of Steam Foam Diverters and Application Methods. SPE paper 18785 presented at SPE California Regional Meeting, Bakersfield, Apr. 5-7, 1989, pp. 399-410. 
28. Shallcross, D.C., L.M. Castanier, and W.E. Brigham. Characterization of Steam Foam Surfactants Through One-Dimensional Sandpack Experiments. Stanford University Petroleum Research Institute Topical Report No. TR 73, Stanford, California. May 1990. Department of Energy Report no. DOE/BC/14126-19. NTIS order No. DE90000235.

29. Marsden, S.S. Foams in Porous Media. Stanford University Petroleum Reseas ch Institute Topical Report No. 49 , July 1986. Department of Energy Report no.DOE/SF/11564-15. NTIS order No. DE8600290.

30. Farouq Ali, S.M. and R.J. Selby. Function, Characteristics of EOR Foam Behavior Covered in Laboratory Investigations. Oil \& Gas J., Feb. 3, 1986, pp. 57-63.

31. Muijs, H.M. and P.P.M. Keijzer. Steam Foam Process. U.S. Patent No. 4,693,311, Sep. $15,1987$.

32. Muijs, H.M., P.P.M. Keijzer, and R.J. Wiersma. Surfactants for Mobility Control in High-Temperature Steam-Foam Applications. SPE paper 17361. Proceedings of the 1988 SPE/DOE Sixth Symposium on Enhanced Oil Recovery, Tulsa, OK, April 1988, pp. $905-914$

33. Lau, H.C. Trona-Enhanced Steam Foam Oil Recovery Process. U.S. Patent No. 4,727,938, Mar. 1, 1988

34. Lau, H.C. and S.M. O'Brien. Foam Drive Oil Displacement with Outlet Pressure Cycling. U.S. Patent No. 4,601,337. July $22,1986$.

35. Lau, H.C., and J.K. Borchardt. Improved Steam Foam Formulations: Concepts and Laboratory Results. SPE 18783. Proceedings of the 1989 SPE California Regional Meeting, Bakersfield, April, 5-7, 1989, pp. 379-388.

36. Dilgren, R.E., G.J. Hirasaki, H.J. Hill, and D.G. Whitten. Steam-Channel-Expanding Steam Foam Drive. U.S. Patent No. 4,086,964, May 2, 1978.

37. Dilgren, R.E. and K.B. Owens. Olefin Sulfonate-Improved Steam Foam Drive. U.S. Patent No. 4,393,937, July 19, 1983.

38. Duerksen, J.H., R.G. Wall, and J.D. Knight. Steam Injection Including Alpha-Olefin Sulfonate Dimer Surfactant Additives and a Process of Stimulating Hydrocarbon Recovery from a Subterranean Formation. U.S. Patent No. 4,556,107. Dec. 3, 1985.

39. Huang, W.S., Z.Z. Gassmann, J.T. Hawkins, V.H. Schievelbein, and W.L. Hall. Method of Improving Conformance in Steam Floods with Steam Foaming Agents. U.S. Patent No. 4,540,050, Sep. 10, 1985.

40. Ploeg, J. F. and J. H. Duerksen. Two Successful Steam/Foam Field Tests, Section 15A and 26C, Midway-Sunset Field. SPE 13609. Proceedings of the __ SPE California Regional Meeting, Bakersfield, March 1985, pp. 219-228.

41. Patzek, T.W. and M.T. Koinis. Kern River Steam Foam Pilots. SPE paper 17380. Proceedings of the 1988 SPE/DOE Sixth Symposium on Enhanced Oil Recovery, Tulsa, OK, April 1988, pp. 663-676.

42. Hirasaki, G.J. The Steam-Foam Process. J. Pet. Tech., v. 41, May 1989. pp. 449-456.

43. Olsen, D.K. Thermal Processes for Heavy Oil Recovery. National Institute for Petroleum and Energy Research Status Report No. NIPER-436, Bartlesville, Oklahoma, Sept 1989.

44. Greaser, G. R. and R. A. Shore. Steamflood Performance in the Kern River Field. Presented at SPE/DOE Enhanced Oil Recovery Symposium, Tulsa, OK, April 1980. SPE/DOE paper 8834.

45. Farrell, H. H., L. B. Plumb and P. H. Lowry. An Evaluation of the Field Demonstration of the Conventional Steam Drive Process With Ancillary Materials at North Kern Front Field. Presented at California Regional Meeting, San Francisco, April 1985. SPE paper 10775 .

46. Doscher, T. M. and E. G. Hammershaimb. Field Demonstration of Steam Drive With Ancillary Material. J. of Pet. Tech., July 1982, pp. $1535-1542$.

47. Mohammadi, S. S. and T. J. McCollum. Steam-Foam Pilot Project in Guadalupe Field, California. Presented at California Regional Meeting of SPE of AIME, April 1986. SPE paper 15044.

48. Mohammadi, S. S., D. C. Van Clyke and B. Ganong. Steam-Foam Pilot Project in Dome-Tumbador, Midway Sunset Field Presented at the SPE Ann. Tech. Conf. and Exhib., Dallas, September 1987. SPE paper 16736. 
49. Chiang, J. C., S. K. Sanyal, L. M. Castanier, W. E. Brigham and A. Sufi. Foam as a Mobility Control Agent on Steam Injection Process. Presented at the SPE California Regional Meeting, San Francisco, March 1982. SPE paper 8912.

50. Malito, O. P., S. K. Sanyal and W. E. Brigham. A Field Experiment of Steam Drive with In-Situ Foaming. Second Annual Report, Oct. 1, 1981-Sept. 30, 1982. Stanford University Petroleum Research Institute, Stanford, California.

51. Olsen, D. K., P. S. Sarathi, S. D. Roark, E. B. Ramzel and S. M. Mahmood. Light Oil Steamflooding: A Laboratory Study of Oil Recovery From Oil and Water-Wet Porous Media from a 2-D Physical Model. To be presented at 2nd Latin American Petroleum Conference, Mar. 8-11, 1992, Caracas, Venezuela. SPE paper 21769.

52. Mahmood. S.M. and W.E. Brigham. Two Dimensional Displacement of Oil by Gas and Surfactant Solution under Foaming Conditions. Stanford University Petroleum Research Institute Topical Report No. 58, July 1987. Department of Energy Report no.DOE/SF/11564-24. NTIS order No. DE87001249. 

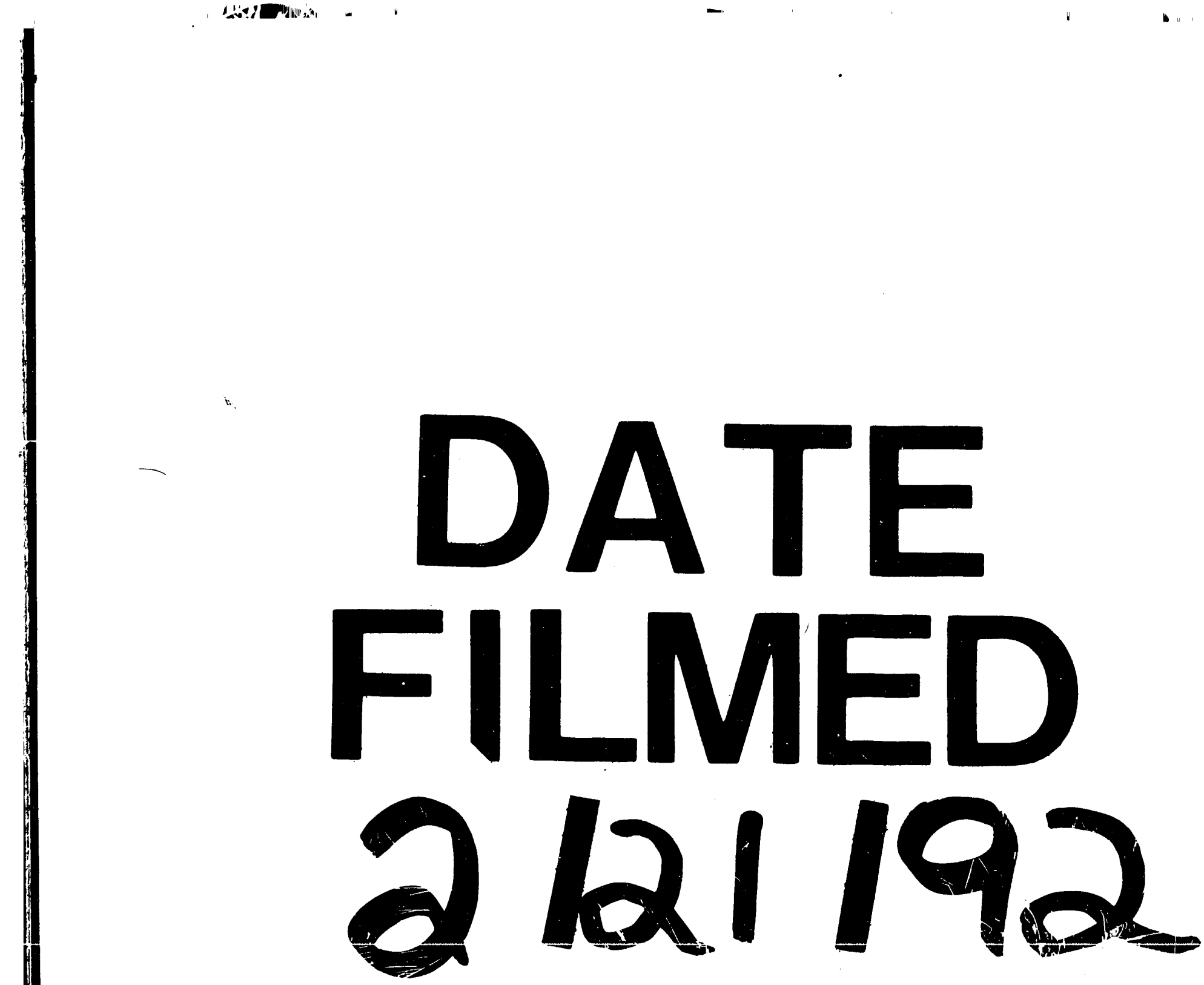

$I$ 
